\title{
Spatial and temporal variation in the diet of Steller sea lions in the Kodiak Archipelago, 1999 to 2005
}

\author{
Jane McKenzie*, Kate M. Wynne \\ University of Alaska Fairbanks, School of Fisheries and Ocean Science, 118 Trident Way, Kodiak, Alaska 99615, USA
}

\begin{abstract}
Spatial and temporal variation in the diet of Steller sea lions Eumetopias jubatus was investigated using scat (fecal) samples collected from 4 regions in the Kodiak Archipelago. Over 2700 scats with identifiable prey were collected from the northern, eastern, southern and western sides of Kodiak Island from 1999 to 2005. Of 76 prey types identified using hard remains, the most important species in terms of frequency of occurrence and numerical abundance were Pacific sand lance Ammodytes hexapterus, walleye pollock Theragra chalcogramma, arrowtooth flounder Atheresthes stomias, Pacific cod Gadus macrocephalus, salmon Oncorhynchus spp., and Pacific herring Clupea pallasi. Significant differences in diet composition were found among regions, seasons, and years, suggesting that the diet of sea lions is strongly influenced by local and temporal distributions and abundances of prey. Herring dominated scat collections from the west coast and accounted for most (14 to $30 \%$ ) of the differences in regional diet in spring and winter. Annual variation in diet was relatively low in winter, whereas spring and fall diets varied from year to year, with regional-specific shifts in dominant prey. Results from our study generally agree with diet studies conducted in the 1990s, but differ markedly in the relative importance of the major prey species.
\end{abstract}

KEY WORDS: Eumetopias jubatus - Prey - Seasonal - Diet overlap - Forage fish - Gulf of Alaska · Theragra chalcogramma $\cdot$ Ammodytes hexapterus

Resale or republication not permitted without written consent of the publisher

\section{INTRODUCTION}

Steller sea lions Eumetopias jubatus are distributed along the North Pacific Rim from northern Japan to central California. The population is divided into 2 genetically distinct population segments (DPSs), the western and eastern DPS, with the boundary near Cape Suckling $\left(144^{\circ} \mathrm{W}\right)$ in the Gulf of Alaska (Loughlin 1997). Between the early 1970s and 2000, the western DPS within Alaska declined by approximately $85 \%$ (Sease et al. 2001), prompting the western population to be listed as 'endangered' under the US Endangered Species Act in 1997. From 1991 to 2000 the average annual rate of decline was approximately $5.4 \%$ (Loughlin \& York 2000), but between 2000 and 2004 the decline appears to have abated in some areas (Fritz \& Stinchcomb 2005). In contrast, the eastern DPS increased at an average annual rate of $3.2 \%$ between 1979 and 2005 (Pitcher et al. 2007) and is currently listed as 'threatened'. The cause or causes of the decline of the western population are unclear. Most hypotheses focus on the effects of a shift in prey availability and composition on the foraging ecology, reproduction and survival of sea lions (DeMaster \& Atkinson 2002, Trites et al. 2007a). Other factors, such as predation by killer whales and incidental take in commercial fisheries may also play a role (National Research Council 2003).

To investigate the impact of changing prey availability on sea lion populations, a number of bioenergetics and trophic models have been developed that explore the relationships between the food requirements of Steller sea lions and the possible impact of commercial fisheries, competition with other species, and ecosystem change (e.g. Winship \& Trites 2003, Guénette et al. 2006). Critical to the development of such models are data on the diet of Steller sea lions. Diet composition of Steller sea lions is known to vary geographically and 
seasonally (Sinclair \& Zeppelin 2002, Waite \& Burkanov 2006). However, due to insufficient data most models have assumed that diet remains constant throughout the year and is similar over broad geographic areas. Recent diet studies in southeast Alaska have indicated considerable spatial, seasonal, and interannual variability in diet over a relatively fine scale (Womble \& Sigler 2006, Trites et al. 2007b). However, fine-scale dietary studies are lacking in western Alaska. These models are also largely based on diet information collected in the 1990s, and therefore may not fully reflect the current status of Steller sea lions in the Gulf of Alaska.

Steller sea lion diet assessment has focused on identifying prey remains in stomach and fecal samples. Prior to the 1990s, Steller sea lion diets were assessed by examination of stomach contents of shot animals, and just over 400 stomachs were collected from 1945 to 1986 (Imler \& Sarber 1947, Mathisen et al. 1962, Thorsteinson \& Lensink 1962, Fiscus \& Baines 1966, Pitcher 1981, Lowry et al. 1982). Considerable effort was made in the 1990s to assess the diet of Steller sea lions in the western range, with the collection of over 3700 scat (fecal) samples throughout the Aleutian Islands and central Gulf of Alaska (Merrick et al. 1997, Sinclair \& Zeppelin 2002). However, individual sitespecific collections were small in number and pooled within 2 broad seasons and across years within datadefined geographical areas. These studies identified a wide range of prey and demonstrated regional and seasonal differences in diet composition across the western range of the population. Comparisons of individual site collections also suggested that, with larger sample sizes, important spatial and temporal differences in diet may be found at a finer scale.

A number of factors may influence the degree of variation in diet composition within and among studies such as sampling techniques (scats vs. stomach contents), sample distribution (sites, months, years), the sex and age of animals from which samples are derived, and interannual variability in prey availability. Despite sampling limitations of historical data, it has been suggested that the diet of Steller sea lions in western Alaska switched from mostly small energyrich schooling fishes (such as herring, capelin, and sand lance) prior to the 1970 s, to mostly gadid species (such as walleye pollock) in the Gulf of Alaska and Atka mackerel in the Aleutians in the 1980s and 1990s (Merrick et al. 1997, Sinclair \& Zeppelin 2002). It was also proposed that diet diversity was lowest where the sharpest decline in the Steller sea lion populations occurred (Merrick et al. 1997), and that diet diversity was a proxy for overall energy content of diet, with low diet diversity equating to low energy content (Winship \& Trites 2003). However, to distinguish between back- ground variation and variation that constitutes an ecologically important change, a greater understanding of the temporal and spatial variation in sea lion diet is required. This requires focused studies that limit temporal and spatial variation in data by standardizing collection efforts and evaluating diet at a finer scale.

The Kodiak Archipelago is located in the westcentral Gulf of Alaska, where population numbers appear to have continued to decline through 2004, although at a slower rate since 1999 (Fritz \& Stinchcomb 2005). Steller sea lions utilize a number of terrestrial sites throughout the archipelago and, as central-place foragers, are likely to be influenced by spatial and temporal availability of prey at a local level. The shelf, coastal, and inside waters of the Kodiak Archipelago present a mosaic of marine habitats, from shallow nearshore areas at the heads of long fjords to deep areas subject to strong tidal currents. Productivity and biodiversity in the region are also influenced by 2 main southwest-flowing current systems: the Alaskan Coastal Current, which passes to the west of Kodiak through the Shelikof Strait, and the Alaskan Stream, which passes along the northeastern coast. Species composition of fish communities on the continental shelf and in nearshore waters around Kodiak Island and adjacent areas vary spatially, but can also change over relatively short periods of time (Anderson \& Piatt 1999, Robards et al. 1999a, Mueter \& Norcross 2000a). We therefore expected that the diet of Steller sea lions in the Kodiak area would vary spatially and temporally on a relatively fine scale.

The specific objectives of our study were (1) to describe the diet of Steller sea lions in the Kodiak Archipelago based on analysis of scats collected between 1999 and 2005 and (2) to assess the extent of geographical, seasonal, and interannual variability in diet. This information will be integrated into future studies to explore relationships between prey availability, diet composition, and haulout use. The data presented will also assist in the refinement of biomass and consumption models for Steller sea lions and will facilitate fine-scale evaluation of the overlap between sea lions and commercial fisheries in the Kodiak region.

\section{MATERIALS AND METHODS}

Sample collection and processing. The Kodiak Archipelago $\left(57^{\circ} 28^{\prime} \mathrm{N}, 153^{\circ} 25^{\prime} \mathrm{W}\right)$ is approximately $240 \mathrm{~km}$ long, extending from Shuyak Island in the north to the Trinity Islands in the south, and is separated from the Alaskan Peninsula by the Shelikof Strait, which averages $48 \mathrm{~km}$ in width. Scats were collected from 8 haulouts (non-breeding areas) and 2 rookeries (breeding areas) in the Kodiak region (Fig. 1) between September 1999 and 


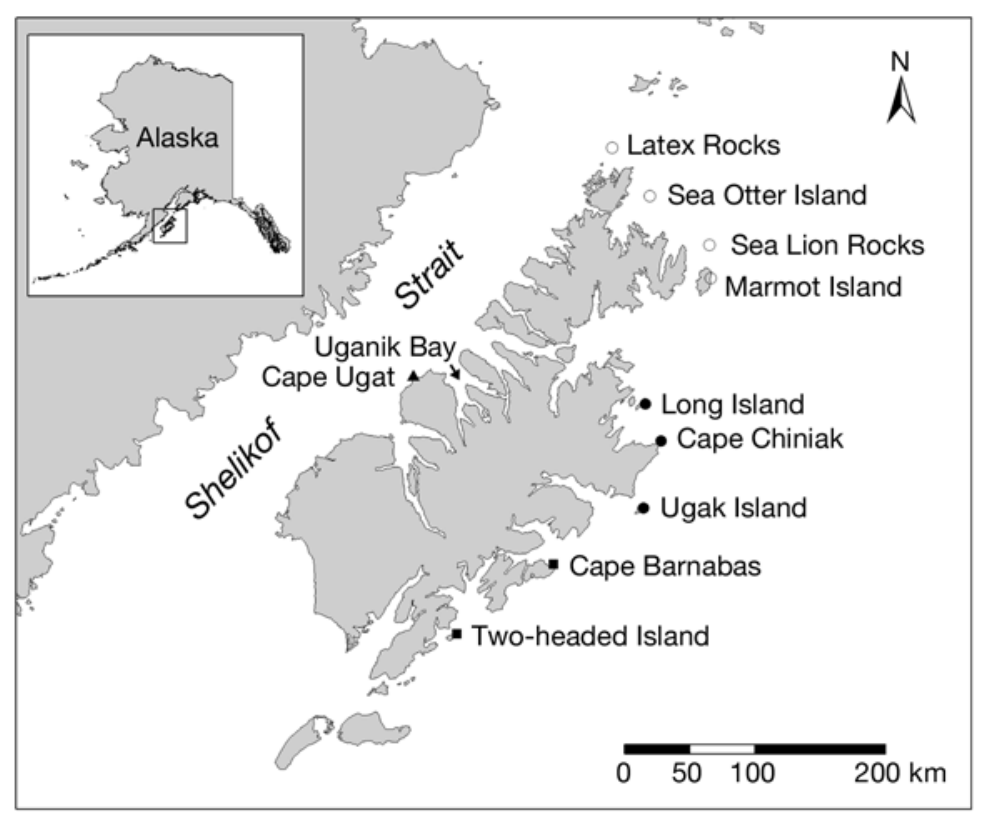

Fig. 1. Sites where Steller sea lion scats were collected in the Kodiak Archipelago from 1999 to 2005. Sites were grouped into 4 geographical regions; north (0), east $(\mathbf{O})$, south $(\mathbf{\square})$, and west $(\boldsymbol{\Delta})$ deposited at sites were assumed to reflect prey consumed in the local area. Scat collections were made monthly, but not all sites or regions were visited each month or season due to logistics, weather conditions, and the need to minimize disturbance (Table 1). Monthly collections were pooled into 4 standard seasons: winter (December to February), spring (March to May), summer (June to August), and fall (September to November), with winter marking the start of a new annual collection. Seasonal collections were complete between 2000 and 2003, but were limited to fall in 1999, winter and fall in 2004, and spring in 2005. For analysis, samples pooled within spatial groups and within seasons were treated as a single collection.

Each scat was placed in a separate plastic bag and frozen at $-20^{\circ} \mathrm{C}$ until processed. Prey remains were separated by soaking thawed scats in soapy water for at least $1 \mathrm{~d}$, and then washing each sample through nested sieves (1.4, 0.7, and $0.5 \mathrm{~mm})$. All hard remains were recovered and stored dry. Diagnostic structures were identified by Pacific Identifications (Victoria, BC, Canada) to the lowest taxonomic level possible by comparison with reference collections. Taxonomic information for prey identified is provided in Table 2. For each scat, the
March 2005. Most sites are used year-round by varying numbers of sea lions of mixed age and sex classes, except for Long Island and Cape Barnabas, which are generally vacated during the summer months (June to August) and Ugak Island, which is used only in summer (Wynne 2005). The 2 rookeries (Marmot and Two-Headed Island) are also used as haulouts by mixed age and sex classes during the non-breeding season. Samples were not collected from Marmot and TwoHeaded Island during the peak of the breeding season (June), and were collected only once in July from TwoHeaded. Therefore, we assessed the diet of non-breeding mixed age and sex classes. To investigate geographical variation in diet, scats collected from individual sites were pooled into 4 spatial groups based on proximity: north (Latex Rocks, Sea Otter Rocks, Sea Lion Rocks, and Marmot Island), east (Long Island, Cape Chiniak, and Ugak Island), south (Cape Barnabas and Two-Headed Island), and west (Cape Ugat) (Fig. 1). Although individual sea lions may move among sites (Merrick \& Loughlin 1997), we have assumed that sea lions haul out at sites closest to or within their most recent foraging area. Thus, scats
Table 1. Number of Steller sea lion scat samples with identifiable prey collected from 4 regions in the Kodiak archipelago (1999 to 2005). For analysis, annual collections commenced in December (winter) of the previous calendar year. Small collections $(<23$ scats) were not used in analysis of spatial and temporal variation in diet composition

\begin{tabular}{|ccccccc|}
\hline \multirow{2}{*}{ Year } & Season & North & East & South & West & Total \\
\hline 1999 & Fall & 27 & 24 & 23 & 26 & 100 \\
2000 & Winter & 119 & 84 & 0 & 39 & 242 \\
& Spring & 52 & 57 & 0 & 2 & 111 \\
& Summer & 73 & 18 & 62 & 0 & 153 \\
& Fall & 38 & 65 & 13 & 0 & 116 \\
2001 & Winter & 110 & 90 & 0 & 35 & 235 \\
& Spring & 55 & 19 & 0 & 48 & 122 \\
& Summer & 77 & 0 & 27 & 6 & 110 \\
& Fall & 203 & 76 & 0 & 39 & 318 \\
2002 & Winter & 28 & 25 & 0 & 31 & 84 \\
& Spring & 51 & 53 & 0 & 34 & 138 \\
& Summer & 34 & 15 & 14 & 53 & 116 \\
& Fall & 177 & 44 & 31 & 48 & 300 \\
2003 & Winter & 0 & 76 & 0 & 0 & 76 \\
& Spring & 48 & 54 & 0 & 43 & 145 \\
& Summer & 75 & 0 & 30 & 17 & 122 \\
\multirow{2}{*}{2004} & Fall & 12 & 26 & 0 & 0 & 38 \\
& Winter & 0 & 29 & 0 & 58 & 87 \\
2005 & Fall & 46 & 0 & 0 & 0 & 46 \\
Total & Spring & 0 & 52 & 0 & 49 & 101 \\
& 1999-2005 & 1225 & 807 & 200 & 528 & 2760 \\
\hline
\end{tabular}


prey type present, minimum number of individual prey, and relative size class of prey were recorded. Empty scats or scats containing only unidentifiable prey were excluded from analysis.

The minimum number of individual prey items (MNI) was estimated as the greatest number of either paired (e.g. otoliths, upper or lower cephalopod beaks, and hypobranchial) or unique structures. Samples that contained only non-unique remains (e.g. non-unique vertebra, teeth, and scales) were recorded as containing a single individual (Browne et al. 2002). Enumer- ated prey were also assigned to relative fork length size (FL $\mathrm{cm}$ ) ranges by Pacific Identifications by comparing diagnostic bone structures with those of a reference collection and a subjective assessment of the level of digestion. To assess the size of prey consumed, prey of a given size range were recorded as present or absent in scat samples, and only data from scats with bone structures in good (pristine to minimal erosion) or fair (moderate erosion not affecting diagnostic features) condition were used. Due to the subjective nature of the size classification and use of overlapping

Table 2. Overall percentage frequency of occurrence (FO), relative occurrence (RO), relative abundance (RA), and index of importance (IIMP) of prey identified in Steller sea lion scats collected from sites in the Kodiak Archipelago (1999 to 2005). Prey

highlighted in bold occurred with $\geq 10 \%$ FO in any single collection. Prey with values of 0.0 indicate actual value was $<0.1$

\begin{tabular}{|c|c|c|c|c|}
\hline Prey identified & $\mathrm{FO}$ & $\mathrm{RO}$ & RA & IIMP \\
\hline Poachers: family Agonidae & 0.5 & 0.2 & 0.1 & 0.1 \\
\hline \multicolumn{5}{|l|}{ Sand lances: family Ammodytidae } \\
\hline Pacific sand lance (Ammodytes hexapterus) & 41.7 & 13.2 & 38.6 & 16.1 \\
\hline \multicolumn{5}{|l|}{ Sablefishes: family Anoplopomatidae } \\
\hline Sablefish (Anoplopoma fimbria) & 0.8 & 0.2 & 0.1 & 0.2 \\
\hline \multicolumn{5}{|l|}{ Tubesnouts: family Aulorhynchidae } \\
\hline Tubesnout (Aulorhynchus flavidus) & 0.7 & 0.2 & 0.1 & 0.1 \\
\hline \multicolumn{5}{|l|}{ Deep sea smelts: family Bathylagidae } \\
\hline Northern smooth tongue (Leuroglossus schmidit) & 0.0 & 0.0 & 0.0 & 0.0 \\
\hline \multicolumn{5}{|l|}{ Ronquils: family Bathymasteridae } \\
\hline Searcher (Bathymaster signatus) & 0.1 & 0.0 & 0.0 & 0.0 \\
\hline Unidentified ronquils (Bathymasteridae) & 0.2 & 0.1 & 0.0 & 0.0 \\
\hline Northern ronquil (Ronquilus jordani) & 0.1 & 0.0 & 0.0 & 0.0 \\
\hline \multicolumn{5}{|l|}{ Herring: family Clupeidae } \\
\hline Pacific herring (Clupea pallasi) & 23.0 & 7.3 & 6.3 & 7.7 \\
\hline \multicolumn{5}{|l|}{ Sculpins: family Cottidae } \\
\hline Artedius spp. & 0.0 & 0.0 & 0.0 & 0.0 \\
\hline Unidentified sculpins & 3.8 & 1.2 & 0.5 & 0.8 \\
\hline Armorhead sculpin (Gymnocanthus galeatus) & 0.0 & 0.0 & 0.0 & 0.0 \\
\hline Red Irish lord (Hemilepidotus hemilepidotus) & 0.3 & 0.1 & 0.0 & 0.1 \\
\hline Yellow Irish lord (Hemilepidotus jordani) & 0.1 & 0.0 & 0.0 & 0.0 \\
\hline Unidentified Irish lord (Hemilepidotus spp.) & 10.8 & 3.4 & 1.6 & 2.4 \\
\hline Plain sculpin (Myoxocephalus jaok) & 0.1 & 0.0 & 0.0 & 0.0 \\
\hline Triglops spp. & 0.0 & 0.0 & 0.0 & 0.0 \\
\hline \multicolumn{5}{|l|}{ Lumpsuckers: family Cyclopteridae } \\
\hline Smooth lumpsucker (Aptocyclus ventricosus) & 0.5 & 0.1 & 0.1 & 0.1 \\
\hline Unidentified lumpsuckers & 1.3 & 0.4 & 0.2 & 0.3 \\
\hline \multicolumn{5}{|l|}{ Sleeper sharks: family Dalatiidae } \\
\hline Pacific sleeper shark (Somniosus pacificus) & 0.0 & 0.0 & 0.0 & 0.0 \\
\hline \multicolumn{5}{|l|}{ Anchovy: family Engraulidae } \\
\hline Anchovy (Engraulis mordax) & 0.0 & 0.0 & 0.0 & 0.0 \\
\hline \multicolumn{5}{|l|}{ Cods: family Gadidae } \\
\hline Saffron cod (Eleginus gracilis) & 0.1 & 0.0 & 0.0 & 0.0 \\
\hline Unidentified gadids (Gadidae) & 10.3 & 3.3 & 1.8 & 3.3 \\
\hline Pacific cod (Gadus macrocephalus) & 31.9 & 10.1 & 5.6 & 9.5 \\
\hline Pacific tomcod (Microgadus proximus) & 0.1 & 0.0 & 0.0 & 0.0 \\
\hline Walleye pollock (Theragra chalcogramma) & 36.8 & 11.6 & 10.9 & 15.1 \\
\hline \multicolumn{5}{|l|}{ Sticklebacks: family Gasterosteidae } \\
\hline Threespine stickleback (Gasterosteus aculaeatus) & 0.4 & 0.1 & 0.1 & 0.1 \\
\hline Sailfin sculpins: family Hemitripteridae & 0.0 & 0.0 & 0.0 & 0.0 \\
\hline \multicolumn{5}{|l|}{ Greenlings: family Hexagrammidae } \\
\hline Unidentified greenlings & 0.5 & 0.2 & 0.1 & 0.1 \\
\hline Hexagrammos spp. & 2.5 & 0.8 & 0.5 & 0.5 \\
\hline Kelp greenling (Hexagrammos decagrammus) & 0.1 & 0.0 & 0.0 & 0.0 \\
\hline Rock greenling (Hexagrammos lagocephalus) & 1.4 & 0.4 & 0.2 & 0.2 \\
\hline Atka mackeral (Pleurogrammus monopterygius) & 0.7 & 0.2 & 0.1 & 0.2 \\
\hline
\end{tabular}


Table 2 (continued)

\begin{tabular}{|c|c|c|c|c|}
\hline Prey identified & $\mathrm{FO}$ & $\mathrm{RO}$ & RA & IIMP \\
\hline Snailfishes: family Liparidae & 6.2 & 2.0 & 1.1 & 1.8 \\
\hline \multicolumn{5}{|l|}{ Lanternfishes: family Myctophidae } \\
\hline Northern lampfish (Stenobrachius leucopsarus) & 0.0 & 0.0 & 0.0 & 0.0 \\
\hline \multicolumn{5}{|l|}{ Smelts: family Osmeridae } \\
\hline Surf smelt (Hypomesus pretiosus) & 0.1 & 0.0 & 0.0 & 0.0 \\
\hline Capelin (Mallotus villosus) & 8.6 & 2.7 & 7.9 & 3.9 \\
\hline Unidentified smelt & 8.9 & 2.8 & 1.3 & 2.1 \\
\hline Eulachon (Thaleichthys pacificus) & 1.1 & 0.3 & 0.2 & 0.2 \\
\hline \multicolumn{5}{|l|}{ Gunnels: family Pholidae } \\
\hline Penpoint gunnel (Apodichthys flavidus) & 0.0 & 0.0 & 0.0 & 0.0 \\
\hline Unidentified gunnel & 1.9 & 0.6 & 0.3 & 0.3 \\
\hline Crescent gunnel (Pholis laeta) & 0.4 & 0.1 & 0.1 & 0.1 \\
\hline \multicolumn{5}{|l|}{ Flatfish: order Pleuronectiformes } \\
\hline Arrowtooth flounder (Atheresthes stomias) & 34.7 & 11.0 & 5.6 & 12.5 \\
\hline Rex sole (Glyptocephalus zachirus) & 0.1 & 0.0 & 0.0 & 0.0 \\
\hline Flathead sole (Hippoglossoides elassodon) & 0.1 & 0.0 & 0.0 & 0.0 \\
\hline Pacific halibut (Hippoglossus stenolepis) & 2.9 & 0.9 & 0.4 & 0.9 \\
\hline Rock sole (Lepidopsetta spp.) & 6.7 & 2.1 & 1.0 & 1.5 \\
\hline Yellowfin sole (Limanda aspera) & 0.0 & 0.0 & 0.0 & 0.0 \\
\hline Sand sole (Lyopsetta exilis) & 0.0 & 0.0 & 0.0 & 0.0 \\
\hline Dover sole (Microstomus pacificus) & 0.2 & 0.1 & 0.0 & 0.0 \\
\hline Starry flounder (Platichthys stellatus) & 0.9 & 0.3 & 0.1 & 0.1 \\
\hline Alaska plaice (Pleuronectes quadrituberculatus) & 0.0 & 0.0 & 0.0 & 0.0 \\
\hline Unidentified flatfish & 8.7 & 2.8 & 1.2 & 2.2 \\
\hline Sand sole (Psettichthys melanostictus) & 0.2 & 0.1 & 0.0 & 0.0 \\
\hline Skates: family Rajidae & 4.6 & 1.5 & 0.6 & 1.0 \\
\hline \multicolumn{5}{|l|}{ Salmonids: family Salmonidae } \\
\hline Pacific salmon (Oncorhynchus spp.) & 26.3 & 8.3 & 4.3 & 8.4 \\
\hline Dolly varden (Salvelinus malma) & 0.1 & 0.0 & 0.0 & 0.0 \\
\hline \multicolumn{5}{|l|}{ Rockfishes: family Scorpaenidae } \\
\hline Unidentified rockfish (Scorpaenidae) & 0.7 & 0.2 & 0.1 & 0.2 \\
\hline Rockfish (Sebastes spp.) & 3.6 & 1.1 & 0.5 & 0.7 \\
\hline Thornyheads (Sebastolobus spp.) & 0.0 & 0.0 & 0.0 & 0.0 \\
\hline \multicolumn{5}{|l|}{ Dogfish sharks: family Squalidae } \\
\hline Spiny dogfish (Squalus acanthias) & 0.9 & 0.3 & 0.1 & 0.2 \\
\hline \multicolumn{5}{|l|}{ Pricklebacks: family Stichaeidae } \\
\hline High cockscomb (Anoplarchus purpurescens) & 0.5 & 0.1 & 0.1 & 0.1 \\
\hline Snake prickelback (Lumpenus sagitta) & 0.0 & 0.0 & 0.0 & 0.0 \\
\hline Unidentified pricklebacks (Stichaeidae) & 1.3 & 0.4 & 0.2 & 0.2 \\
\hline Arctic shanny (Stichaeus punctatus) & 0.0 & 0.0 & 0.0 & 0.0 \\
\hline Black prickleback (Xiphister atropurpures) & 0.0 & 0.0 & 0.0 & 0.0 \\
\hline Rock prickelback (Xiphister mucosus) & 0.0 & 0.0 & 0.0 & 0.0 \\
\hline Prickelback (Xiphister spp.) & 0.1 & 0.0 & 0.0 & 0.0 \\
\hline \multicolumn{5}{|l|}{ Sandfishes: family Trichodontidae } \\
\hline Pacific sandfish (Trichodon trichodon) & 10.5 & 3.3 & 2.8 & 2.5 \\
\hline \multicolumn{5}{|l|}{ Eelpouts: family Zoarchidae } \\
\hline Shortfin eelpout (Lycodes brevipes) & 0.0 & 0.0 & 0.0 & 0.0 \\
\hline Wattled eelpout (Lycodes palearis) & 0.0 & 0.0 & 0.0 & 0.0 \\
\hline Unidentified fish spp. & 3.1 & 1.0 & 0.4 & 1.0 \\
\hline \multicolumn{5}{|l|}{ Squids and octopus: Order Cephalopoda } \\
\hline Unidentified cephalopods & 2.1 & 0.7 & 0.3 & 0.4 \\
\hline Octopus spp. & 2.8 & 0.9 & 0.4 & 0.6 \\
\hline Squid spp. & 0.6 & 0.2 & 0.1 & 0.1 \\
\hline Marine worm: class Polychaete & 8.0 & 2.5 & 3.7 & 2.0 \\
\hline Total & & 100 & 100 & 100 \\
\hline \multicolumn{5}{|l|}{ Samples (total) } \\
\hline \multicolumn{5}{|l|}{ Scats containing identifiable prey (2760) } \\
\hline \multicolumn{5}{|l|}{ Scats containing only unidentifiable prey (192) } \\
\hline \multicolumn{5}{|l|}{ Empty scats (80) } \\
\hline Total collected (3032) & & & & \\
\hline
\end{tabular}


length ranges, the size of primary prey consumed by sea lions was assessed at a broad scale only. Detailed assessments of the size of some prey species consumed by Steller sea lions have been reported elsewhere and require the accurate measurement of selected cranial structures and the application of digestive correction factors (Tollit et al. 2004, Zeppelin et al. 2004) unavailable in our study.

Data analyses. Diet composition and the relative importance of each prey type were assessed using 3 standard indices expressed as percentages: frequency of occurrence (FO: proportion of scats with identifiable prey containing a given prey type), relative occurrence (RO: proportion of total occurrences of prey made up of each prey type), and relative abundance (RA: proportion of the total number of prey items made up of each prey type). Relative occurrence gives the same relative value as FO, but, unlike FO, sums to $100 \%$ and allows direct comparison between collections and other indices. We also calculated an index of importance (IIMP), which combines information on both occurrence and abundance. The percentage IIMP was calculated following García-Rodríquez \& Aurioles-Gamboa (2004) as:

$$
\operatorname{IIMP}_{j}=100 \times\left[\frac{1}{U} \sum_{j=1}^{U} \frac{X_{i j}}{X_{j}}\right]
$$

where $X_{i j}$ is the number of individuals (MNI) of prey type $i$ in scat $j, X_{j}$ is the total number of individuals from all prey found in scat $j$, and $U$ is the total number of scats in the sample with identifiable prey. Although the importance of each prey type in diet studies is best represented by volumetric data (Hyslop 1980), biomass contribution was not calculated in the present study due to the subjective method of size classification employed and lack of species-specific numerical correction factors.

Diet diversity was estimated for each collection using the Shannon's index of diversity, $H^{\prime}$, based on frequency of occurrence. To compare diversity on a linear scale, the exponential of the Shannon entropy value was calculated to give the effective number of species (ENS: the number of equally common species required to give a particular value of the diversity index; MacArthur 1965). To compare diet diversity with previous Steller sea lion dietary studies, prey were grouped into 7 categories following Merrick et al. (1997): gadids, salmon, forage fish, hexagrammids, flat fish, cephalopods, and others. Shannon's index of diversity was then calculated using the split-sample frequency of occurrence (SSFO) following Merrick et al. (1997). The exponential of the Shannon entropy value, referred to by Merrick et al. (1997) as the diet diversity index (DDI), ranges from 1 (1 prey group in the diet) to 7 (all 7 prey groups). To compare our esti- mates of DDI with those for southeast Alaska in the 1990s, seasonal DDI values were calculated from the SSFO data presented for the 7 prey categories in Winship \& Trites (2003).

The similarity or overlap in diet composition among regional and seasonal collections was quantified using the Bray-Curtis coefficient of similarity $(S)$ (Bray \& Curtis 1957). The value of $S$ ranges from 0 to $1 ; S=0$ indicates no overlap in prey use and $S=1$ indicates perfect overlap in prey use. Two collections were considered relatively similar for $S \geq 60 \%$, based on examination of multi-dimensional scaling (MDS) plots and dendograms of collections (PRIMER v. 5). An MDS stress factor of $<0.2$ was assumed to indicate that the MDS plot was an accurate representation of the relationships between collections (Schiffman et al. 1981). Rare species were not removed from analysis, as the similarity measure used automatically down-weighted the contribution of less common species.

Cumulative prey curves were constructed to evaluate the adequacy of sample sizes to represent diet composition. Each was constructed using randomization procedures (EstimateS v. 8) based on the occurrence of primary prey. To reduce the influence of exceptionally rare or secondarily consumed species, prey that occurred in $\leq 5 \%$ of samples in any one collection were excluded. Sample-based curves were plotted by calculating the means of the number of prey identified, following repeated re-sampling of scats without replacement and 100 randomizations of scat order. Sampling adequacy was evaluated by visual inspection of curve stabilization. Prey accumulation curves were calculated for each season within the 4 regions using collections pooled across years.

Statistical analysis. The relative rank of prey types were compared between indices of importance using the Spearman's rank correlation coefficient $\left(\mathrm{r}_{\mathrm{s}}\right)$, and the Mann-Whitney $U$-test was used to test for significant differences in $H^{\prime}$ among seasons and regions (SPSS v. 13.0). Mean values are given $( \pm$ SD). Overall differences in diet between regions and between seasons within each region were statistically tested using nonparametric analysis of similarities (ANOSIM) on the Bray-Curtis similarities matrices (PRIMER v. 5) and 999 randomizations of collections. ANOSIM tests the null hypothesis that within-group similarities do not exceed between-group similarities. This test has a number of advantages over univariate tests and does not assume variability of within-group replications is similar for all groups. Where significant differences between groups were found, pair-wise tests were used to identify the main differences. Due to a limited number of collections (replicates) in some comparisons the value of the test statistic $\mathrm{R}$ was used to assess betweengroup differences, where mid- to high-range values of 
$\mathrm{R}$ are indicative of complete separation of groups and values close to zero imply little or no difference (Clarke \& Warwick 2001). All other statistical analysis used a significance level of $\alpha=0.05$. The main species contributing to the observed differences were determined based on their relative contribution to the average Bray-Curtis dissimilarity between groups, using similarity of percentage (SIMPER) analysis (PRIMER v. 5). Only species contributing to $\geq 10 \%$ of the observed dissimilarity between groups are listed. Only collections where $>1$ region was sampled for a given year and season were included in analysis of similarity. Due to the limited number of collections available for the southern region, ANOSIM was restricted to comparisons among north, east, and west collections, unless stated otherwise. Analysis performed using IIMP did not alter general conclusions, although the rank of discriminating prey varied slightly. Only statistical analyses based on RO are presented here.

\section{RESULTS}

\section{Sample distribution}

A total of 2760 scats containing identifiable prey remains were collected from September 1999 through March 2005 (Table 1). Scat collection was affected by seasonal changes in Steller sea lion Eumetopias jubatus distribution and haulout accessibility. As a consequence, the size and number of collections were variable across sites, seasons, and years. Most scats were collected from sites in the north $(44.4 \%)$, east $(29.2 \%)$, and west $(19.1 \%)$, whereas the number of scats from the south was small $(7.2 \%)$ and limited to summer and fall. Collections were largely biased towards the non-breeding season, with summer collections contributing to only $18.2 \%$ of the total number of scats. Scats collected in summer were primarily from the north $(51.7 \%)$ and south $(26.5 \%)$. Overall, $87.9 \%$ of scats were collected between 2000 and 2003, with seasonal collections incomplete in 1999, 2004, and 2005.

\section{Summary of diet composition}

In total, 76 prey types were identified: 48 to species level, 11 to genus, 13 to family, 1 to class, 2 to order and 1 to group (Table 2). Fish remains were found in all scats with identifiable prey: cephalopods in $5.4 \%$, and polychaete worms in $8.0 \%$. Crustacean remains consisting of carapace fragments of crabs, isopods, and euphausids were noted in a large number of scats, but were not included in analysis due to difficulties in enu- meration, advanced degradation, and variable effort in identification over the study period. Overall, unidentified fish were recorded in $3 \%$ of scats and ranged from 0 to $9 \%$ among collections.

When samples were pooled across years, seasons, and regions, 9 main prey types were identified with FO $\geq 10 \%$ (Table 2). Pacific sand lance Ammodytes hexapterus (hereafter referred to as sand lance), walleye pollock Theragra chalcogramma (hereafter referred to as pollock) and arrowtooth flounder Atheresthes stomias were the most common prey, occurring in 35 to $42 \%$ of all scats. Pacific cod Gadus macrocephalus, salmon Oncorhynchus spp. and Pacific herring Clupea pallasi (hereafter referred to as herring) occurred in 23 to $32 \%$ of scats, and Irish lords Hemilepidotus spp., Pacific sandfish Trichodon trichodon, and unidentified gadids (family Gadidae) occurred in 10 to $11 \%$ of scats. Based on a minimum number of 8730 individual prey identified, the most numerically abundant prey was sand lance $(39 \%)$, followed by pollock (11\%), capelin $(8 \%)$, herring $(6 \%)$, arrowtooth flounder $(6 \%)$, and Pacific cod (6\%) (Table 2). On average, sand lance and capelin were the most abundant prey per scat when present (Table 3). The mean number of prey types identified per scat was $3.2 \pm 2.1$ and ranged from 1 to 19 prey types. Of the scats containing a single identifiable prey $(\mathrm{n}=622)$, most contained pollock $(20.7 \%)$, arrowtooth flounder (19.5\%), or salmon (12.4\%). Sand lance was the prey most frequently co-occurring in scats containing Pacific cod $(61.5 \%)$, salmon $(60.2 \%)$, herring (50.9\%), and pollock (50.0\%). In scats containing arrowtooth flounder, sand lance and pollock cooccurred in similar proportions (47.8 and 47.2\%, respectively).

The relative importance of each prey type based on the 3 indices (RO, RA, and IIMP) was similar, with only a few principle discrepancies (Table 3). Capelin was ranked as the third most important prey based on relative abundance, but only the tenth in regard to their occurrence. In terms of IIMP, capelin was ranked seventh, indicating that although capelin occurred less frequently than other main prey, they consistently occurred in relatively high abundance when present in scats. Polychaete worms were also ranked higher in importance based on abundance compared to occurrence. However, examination of the distribution of MNI indicated that RA was dominated by 2 scats containing 106 and 133 individuals, whereas most scats in which polychaetes were present contained 1 to 3 individuals. Thus, their overall ranking based on IIMP was much lower and similar to that based on RO. Irish lords were also ranked slightly lower in terms of RA and IIMP compared to RO, reflecting that although common, most samples $(90 \%)$ contained only 1 individual. Although IIMP was highly correlated with both 
RO ( $\left.\mathrm{r}_{\mathrm{s}}=0.980, \mathrm{p}=0.000, \mathrm{n}=24\right)$ and RA $\left(\mathrm{r}_{\mathrm{s}}=0.964\right.$, $\mathrm{p}=0.000, \mathrm{n}=24)$, the stronger relationship with RO reflected the greater influence of occurrence on IIMP and down-weighting of individual scats with unusually high abundances of a given prey.

Sand lance recovered from scats were estimated to range in size from $<7$ to $27 \mathrm{~cm}$ FL and were grouped into 3 size categories: $\leq 7 \mathrm{~cm}$ (small), 8 to $19 \mathrm{~cm}$ (medium), and 20 to $27 \mathrm{~cm}$ (large). Of scats, $83 \%$ contained medium-sized sand lance, 22\% large sand lance, and $20 \%$ small sand lance. Pollock recovered in scats were estimated to range in length from $<8$ to 54 $\mathrm{cm}$ FL and were grouped into the 3 size and age classes: juvenile $(\leq 20 \mathrm{~cm})$, subadult $(21$ to $34 \mathrm{~cm})$, and adult $(\geq 35 \mathrm{~cm}$ ) (Hughes \& Hirschhorn 1979, DiCosimo $\&$ Kimball 2001). Overall, subadult pollock (60\%) were the most dominant age class based on frequency of occurrence, followed by adult (37\%) and juvenile (35\%) pollock. Arrowtooth flounder ranged in size from $<16$ to $70 \mathrm{~cm}$, with $91 \%$ of scats containing flounder estimated to be within the range of 25 to $59 \mathrm{~cm}$. Pacific cod ranged in size from $<8$ to $69 \mathrm{~cm} \mathrm{FL}$, and most scats (94\%) contained fish $\geq 27 \mathrm{~cm}$, with $69 \%$ of scats containing cod within the 50 to $69 \mathrm{~cm}$ range. Salmon in scats were estimated to range in length from $<15$ to $90 \mathrm{~cm}$, with a major peak in size distribution at
30 to $59 \mathrm{~cm}$ and a smaller peak at 16 to $29 \mathrm{~cm}$. Capelin ranged in size from $<5$ to $18 \mathrm{~cm} \mathrm{FL,} \mathrm{with} 94 \%$ of scats containing capelin 10 to $18 \mathrm{~cm}$ in length. Herring ranged in size from $<8$ to $35 \mathrm{~cm} \mathrm{FL}$, with most scats (97\%) containing herring 11 to $35 \mathrm{~cm}$ in length.

Cumulative prey curves indicated that the relative increase in the number of new prey identified per additional scat was small ( $<2 \%$ ) following examination of 23 scats (Fig. 2). To reduce biases in diet composition due to small sample size, while retaining a sufficient number of collections for spatial and temporal comparisons, collections with $<23$ scats were excluded from further analysis. This size was considered sufficient to describe the relative contribution of the main prey species to the Steller sea lion diet. The mean sample size of scats retained in the analysis was $56.3 \pm 36.1$, with most $(70 \%)$ collections containing $>35$ scats.

Examination of individual collections suggested that species composition and relative importance of prey varied by region, season, and year (Figs. 3 \& 4, Appendix 1, available as MEPS Supplementary Material at: www.int-res.com/articles/suppl/m360p265_app.pdf). A total of 24 prey occurred with $\geq 10 \%$ FO in any 1 collection (Table 3 ). Twelve prey had IIMP values $\geq 10 \%$ in any 1 collection (Table 3 ) and accounted for $78 \%$ of identifiable prey by occurrence and $90 \%$ by number.

Table 3. Primary prey ( $\geq 10 \%$ frequency of occurrence for any collection), ranked by percentage relative occurrence (RO), relative abundance (RA), and index of importance (IIMP). The minimum number of individuals (MNI) per scat when present is given as a mean and range. Values are for all 2760 scats pooled. Prey highlighted in bold had IIMP values $\geq 10 \%$ in any 1 collection. Primary habit(s) (P: pelagic; D: demersal; S: schooling) were assigned following Mecklenburg et al. (2002)

\begin{tabular}{|c|c|c|c|c|c|c|c|c|c|}
\hline \multirow[t]{2}{*}{ Prey type } & \multirow[t]{2}{*}{ Habit } & \multirow[t]{2}{*}{$\mathrm{RO}$} & \multirow[t]{2}{*}{ (Rank) } & \multirow[t]{2}{*}{ RA } & \multirow[t]{2}{*}{ (Rank) } & \multirow[t]{2}{*}{ IIMP } & \multirow[t]{2}{*}{ (Rank) } & \multicolumn{2}{|c|}{ MNI per scat } \\
\hline & & & & & & & & Mean & Range \\
\hline Pacific sand lance & PDS & 13.2 & (1) & 38.6 & (1) & 16.1 & (1) & 7.1 & $1-394$ \\
\hline Walleye pollock & PD & 11.6 & (2) & 10.9 & $(2)$ & 15.1 & $(2)$ & 2.3 & $1-74$ \\
\hline Arrowtooth flounder & $\mathrm{D}$ & 11.0 & (3) & 5.6 & (5) & 12.5 & (3) & 1.2 & $1-7$ \\
\hline Pacific cod & PDS & 10.1 & (4) & 5.6 & (5) & 9.5 & (4) & 1.4 & $1-19$ \\
\hline Pacific salmon & $\mathrm{PD}$ & 8.3 & (5) & 4.3 & (6) & 8.4 & (5) & 1.3 & $1-11$ \\
\hline Pacific herring & PS & 7.3 & (6) & 6.3 & (4) & 7.7 & (6) & 2.1 & $1-44$ \\
\hline Irish lord, unidentified & $\mathrm{D}$ & 3.4 & (7) & 1.6 & (10) & 2.4 & (10) & 1.1 & $1-4$ \\
\hline Pacific sandfish & $\mathrm{D}$ & 3.3 & (8) & 2.8 & (8) & 2.5 & (9) & 2.1 & $1-34$ \\
\hline Gadids, unidentified & PDS & 3.3 & (8) & 1.8 & (9) & 3.3 & (8) & 1.3 & $1-29$ \\
\hline Smelt, unidentified & $\mathrm{P}$ & 2.8 & (9) & 1.3 & (11) & 2.1 & (12) & 1.1 & $1-3$ \\
\hline Flatfish, unidentified & $\mathrm{D}$ & 2.8 & (9) & 1.2 & $(12)$ & 2.2 & (11) & 1.1 & $1-4$ \\
\hline Capelin & PS & 2.7 & (10) & 7.9 & (3) & 3.9 & $(7)$ & 7.0 & $1-128$ \\
\hline Polychaete worm & $\mathrm{D}$ & 2.5 & (11) & 3.7 & (7) & 2.0 & (13) & 3.5 & $1-133$ \\
\hline Rock sole & $\mathrm{D}$ & 2.1 & (12) & 1.0 & (14) & 1.5 & (15) & 1.1 & $1-4$ \\
\hline Snailfishes, unidentified & $\mathrm{D}$ & 2.0 & (13) & 1.1 & (13) & 1.8 & (14) & 1.4 & $1-8$ \\
\hline Skates & $\mathrm{D}$ & 1.5 & (14) & 0.6 & (15) & 1.0 & (16) & 1.0 & 1 \\
\hline Sculpins, unidentified & $\mathrm{D}$ & 1.2 & (15) & 0.5 & (16) & 0.8 & (18) & 1.1 & $1-2$ \\
\hline Rockfish & $\mathrm{D}$ & 1.1 & (16) & 0.5 & (16) & 0.7 & (19) & 1.0 & 1 \\
\hline Pacific halibut & $\mathrm{D}$ & 0.9 & $(17)$ & 0.4 & (15) & 0.9 & (17) & 1.1 & $1-2$ \\
\hline Hexagrammos spp. & $\mathrm{D}$ & 0.8 & $(18)$ & 0.5 & $(16)$ & 0.5 & $(20)$ & 1.6 & $1-16$ \\
\hline Gunnel, unidentified & $\mathrm{D}$ & 0.6 & (19) & 0.3 & $(14)$ & 0.3 & $(21)$ & 1.2 & $1-3$ \\
\hline Lumpsucker, unidentified & $\mathrm{PD}$ & 0.4 & $(20)$ & 0.2 & (13) & 0.3 & (21) & 1.0 & 1 \\
\hline Eulachon & $\mathrm{P}$ & 0.3 & (21) & 0.2 & (13) & 0.2 & $(20)$ & 1.3 & $1-2$ \\
\hline Smooth lumpsucker & $\mathrm{PD}$ & 0.1 & $(22)$ & 0.1 & (12) & 0.1 & (19) & 1.5 & $1-4$ \\
\hline
\end{tabular}




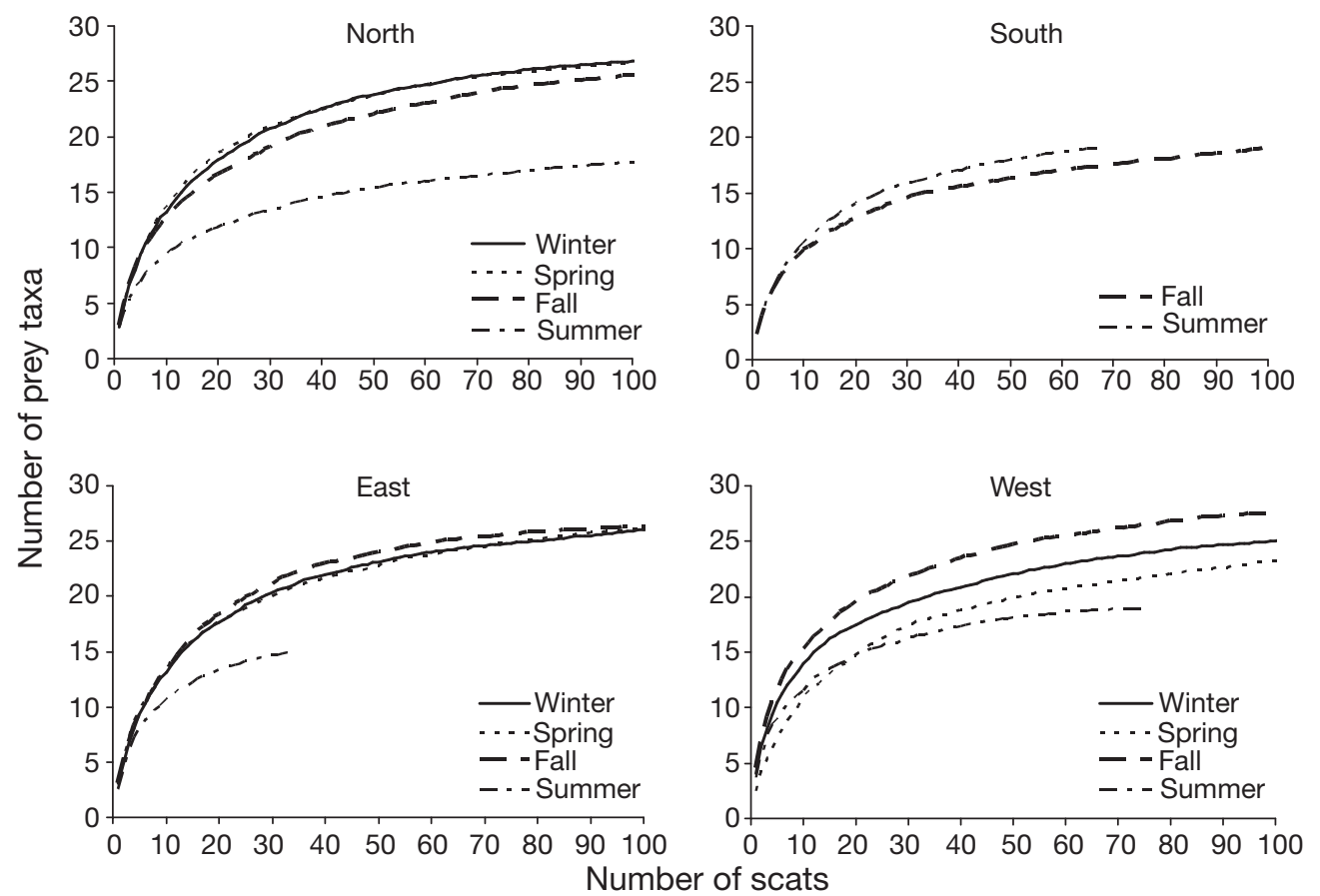

Fig. 2. Cumulative curves of the mean number of prey types identified in Steller sea lion scats collected in 4 regions of the Kodiak Archipelago (1999 to 2005). Cumulative curves were constructed using randomization procedures (100 times), without replacement

North

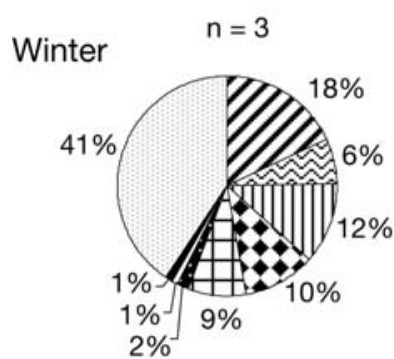

$\mathrm{n}=4$

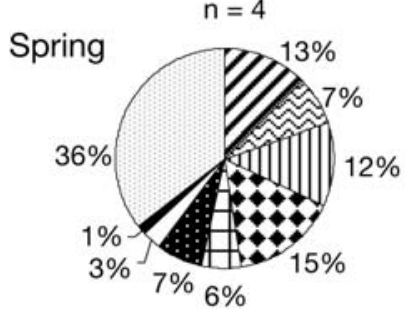

Fall

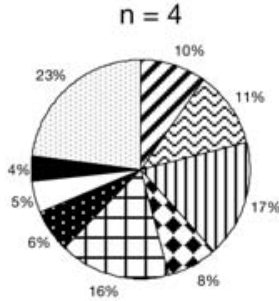

East

$n=4$

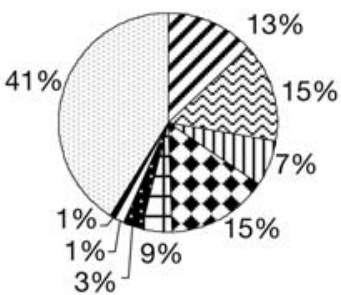

$\mathrm{n}=4$

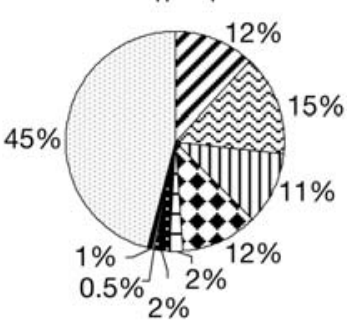

$\mathrm{n}=4$

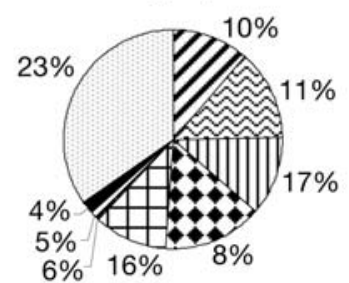

West

$\mathrm{n}=4$
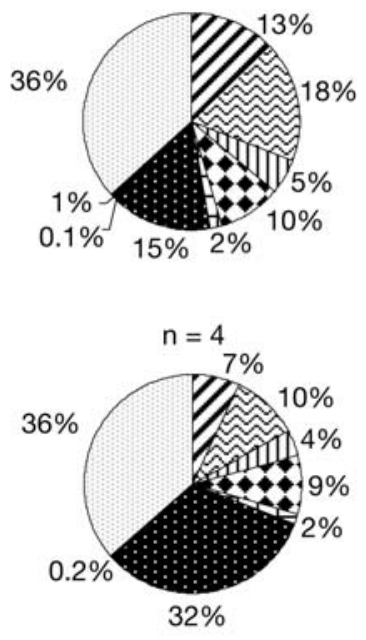

$\mathrm{n}=3$

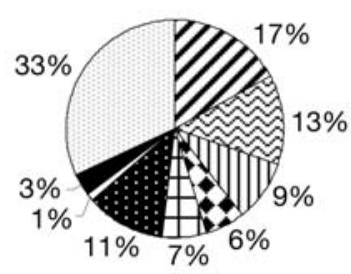

Pacific sand lance

Walleye pollock

III Arrowtooth flounder

Pacific cod

E Pacific salmon

a Pacific herring

Capelin

Smelts, unidentified

Other

Fig. 3. Relative contribution (based on occurrence) of 8 main prey species to the average diet com- position of Steller sea lions, based on scats collected from the northern, eastern, and western regions of the Kodiak Archipelago (1999 to 2005). Number above each pie chart is the number of annual collections used for analysis of similarity for regional comparisons 

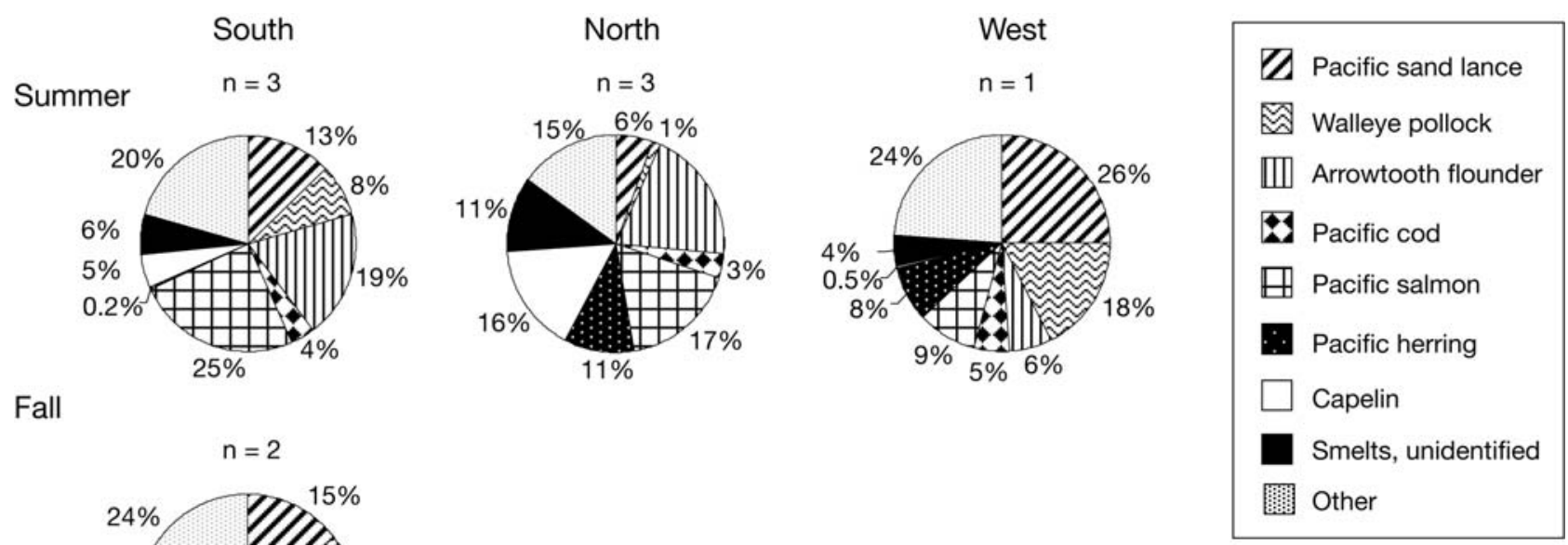

Fall

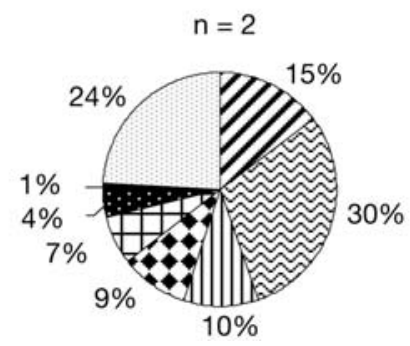

\begin{abstract}
Fig. 4. Relative contribution (based on occurrence) of 8 main prey species to the average fall and summer diet composition of Steller sea lions, based on scats collected from the southern, northern, and western regions of the Kodiak Archipelago (1999 to 2003). Number above each pie chart is the number ofannual collections used for analysis of similarity for regional comparisons
\end{abstract}

\section{Regional variation in diet composition}

Using the Bray-Curtis similarity matrices based on the relative occurrence of prey, differences in diet composition among regions were significant within each season (Table 4, Figs. $3 \& 4$ ). In winter, diet composition was similar between collections from the north and east (mean $S=64.5 \%$; $\mathrm{R}=0.20, \mathrm{p}=0.114$ ), but significantly different between the west and north (mean $S=53.7 \%$; $\mathrm{R}=0.87, \mathrm{p}=0.029$ ), and west and east (mean $S=61.3 \%$; $\mathrm{R}=0.45, \mathrm{p}=0.029 ;$ Fig. 3 ). The most common prey in all 3 regions in winter were sand lance, pollock, Pacific cod, and arrowtooth flounder, although they occurred in different proportions among regions and years (Fig. 3, Appendix 1A, B, C). Differences in winter diet among regions were largely attributed to the relatively high occurrence of herring in the west (accounting for 14 and $16 \%$ of the difference between north and east, respectively) and a relatively low occurrence of pollock in the north compared to the west (12\% of the difference).

As in winter, spring diet composition was similar in the north and east (mean $S=61.5 \%$; R $=0.18$, $\mathrm{p}=0.143$ ), but differed significantly between north and west (mean $S=$ $47.0 \% ; \mathrm{R}=0.98, \mathrm{p}=0.029)$ and east and west (mean $S=49.6 \%$; $\mathrm{R}=0.99$, p $=0.029$; Fig. 3). The most common prey among the 3 regions in spring were similar to winter (Fig. 3). Differences in spring diet composition between regions were largely due to a relatively high occurrence of herring in the west compared to in the north and east ( 24 and $30 \%$ of the difference, respectively; Fig. 3).
In fall, only the composition of east and west diets differed significantly (mean $S=57.7 \%$; $=0.61, \mathrm{p}=$ 0.029); diet composition in the north was similar to that in the west (mean $S=58.9 \% ; \mathrm{R}=0.24, \mathrm{p}=0.143$ ) and east (mean $S=61.7 \%$ R $=0.04, \mathrm{p}=0.286$ ). The most common prey in all 3 regions in fall were pollock, arrowtooth flounder, sand lance, and salmon, although they occurred in different proportions among regions and years (Fig. 3, Appendix 1A, B, C). Variation in diet between east and west was largely attributed to a relatively higher occurrence of herring (13\% of difference) and sand lance $(11 \%$ of difference) in the west, and a higher occurrence of Pacific cod in the east (11\% of difference). Although the average diet composition in the north appeared to be different from that in the east and west (Fig. 3), interannual variation in fall diet in the north was greater than the differences between regions (Table 5). Limited fall collections in the south precluded statistical analysis using ANOSIM, but overlap in diet between the south and all other regions was low

Table 4. Analysis of similarity of diet composition of Steller sea lion scat collections within and among regions and seasons. The numbers of collections used in each analysis are listed (n)

\begin{tabular}{|lclccc|}
\hline Comparison & Season/location & Location/season & Global R & $\mathrm{p}$ & $\mathrm{n}$ \\
\hline Regional & Winter & North, East, West & 0.503 & 0.004 & 11 \\
& Spring & North, East, West & 0.762 & 0.003 & 12 \\
& Fall & North, East, West & 0.243 & 0.028 & 11 \\
& Summer & North, South & 0.444 & 0.100 & 6 \\
Seasonal & North & All & 0.496 & 0.004 & 16 \\
& East & Excludes summer & 0.03 & 0.287 & 14 \\
& West & Excludes summer & 0.73 & 0.001 & 11 \\
\hline
\end{tabular}


Table 5. Bray-Curtis overlap (similarity) indices matrix for the diet composition of Steller sea lion scat collections among regions and years within each season. Numbers in bold indicate low similarity in diet $(S<60 \%)$. Solid boxes highlight annual similarity withineach region and dashed boxes highlight between-region similarities

\begin{tabular}{|c|c|c|c|c|c|c|c|c|c|c|c|c|c|c|}
\hline Winter & $\begin{array}{c}\text { North } \\
00\end{array}$ & $\begin{array}{c}\text { North } \\
01\end{array}$ & $\begin{array}{c}\text { North } \\
02\end{array}$ & $\begin{array}{c}\text { East } \\
00\end{array}$ & $\begin{array}{c}\text { East } \\
01\end{array}$ & $\begin{array}{c}\text { East } \\
02\end{array}$ & $\begin{array}{c}\text { East } \\
03\end{array}$ & $\begin{array}{c}\text { East } \\
04\end{array}$ & $\begin{array}{c}\text { West } \\
00\end{array}$ & $\begin{array}{c}\text { West } \\
01\end{array}$ & $\begin{array}{c}\text { West } \\
02\end{array}$ & & & \\
\hline North 01 & 76.6 & & & & & & & & & & & & & \\
\hline North 02 & 60.5 & 72.1 & & & & & & & & & & & & \\
\hline East 00 & 78.2 & 74.2 & 61.4 & & & & & & & & & & & \\
\hline East 01 & 72.0 & 72.8 & 58.1 & 78.5 & & & & & & & & & & \\
\hline East 02 & 79.7 & 70.6 & 55.8 & 80.7 & 71.9 & & & & & & & & & \\
\hline East 03 & 65.3 & 58.4 & 45.5 & 72.0 & 70.9 & 70.8 & & & & & & & & \\
\hline East 04 & $\begin{array}{ll}53.3 \\
\end{array}$ & 51.9 & 46.4 & 58.8 & 61.2 & 52.0 & 63.5 & & & & & & & \\
\hline West 00 & 66.1 & 57.0 & $\mathbf{5 3 . 0}$ & 70.4 & 67.2 & 70.7 & 64.8 & $\mathbf{5 3 . 6}$ & & & & & & \\
\hline West 01 & 5 & 53.0 & 47.1 & 65.1 & 63.4 & 63.1 & 67.4 & 56.7 & 75.5 & & & & & \\
\hline West 02 & 44.5 & 37.7 & 40.2 & 50.9 & 50.7 & 56.5 & 56.8 & 41.6 & 67.6 & 64.6 & & & & \\
\hline West 04 & 65.0 & 65.7 & 55.9 & 73.6 & 71.3 & 67.2 & 59.4 & 58.7 & 75.4 & 73.2 & 65.8 & & & \\
\hline Spring & $\begin{array}{c}\text { North } \\
00\end{array}$ & $\begin{array}{c}\text { North } \\
01\end{array}$ & $\begin{array}{c}\text { North } \\
02\end{array}$ & $\begin{array}{c}\text { North } \\
03\end{array}$ & $\begin{array}{c}\text { East } \\
00\end{array}$ & $\begin{array}{c}\text { East } \\
02\end{array}$ & $\begin{array}{c}\text { East } \\
03\end{array}$ & $\begin{array}{c}\text { East } \\
05\end{array}$ & $\begin{array}{c}\text { West } \\
01\end{array}$ & $\begin{array}{c}\text { West } \\
02\end{array}$ & $\begin{array}{c}\text { West } \\
03\end{array}$ & & & \\
\hline North 01 & 58.2 & & & & & & & & & & & & & \\
\hline North 02 & 53.0 & 70.2 & & & & & & & & & & & & \\
\hline North 03 & 64.2 & 57.6 & 70.2 & & & & & & & & & & & \\
\hline East 00 & 56.6 & 68.4 & 70.6 & $\mathbf{5 8 . 2}$ & & & & & & & & & & \\
\hline East 02 & $\begin{array}{l}43.9 \\
\end{array}$ & 52.3 & 60.7 & 56.4 & 65.4 & & & & & & & & & \\
\hline East 03 & $\begin{array}{l}54.4 \\
\end{array}$ & 59.8 & 75.7 & 67.2 & 70.8 & 64.3 & & & & & & & & \\
\hline East 05 & 58.4 & 71.9 & 69.3 & 60.7 & 79.3 & 57.6 & 64.2 & & & & & & & \\
\hline West 01 & 52.9 & 45.4 & 50.2 & 52.6 & 53.3 & 59.7 & 46.2 & 57.5 & & & & & & \\
\hline West 02 & 50.6 & 36.6 & 48.5 & 47.3 & 50.4 & 49.6 & 47.5 & 46.6 & 62.5 & & & & & \\
\hline West 03 & 45.7 & 30.6 & 40.2 & 44.7 & 43.8 & 48.2 & 41.7 & 39.7 & 62.3 & 77.0 & & & & \\
\hline West 05 & 52.9 & 42.5 & 53.4 & 57.5 & 52.3 & 54.8 & 50.6 & 51.7 & 73.6 & 72.0 & 75.6 & & & \\
\hline Fall & $\begin{array}{c}\text { North } \\
99\end{array}$ & $\begin{array}{c}\text { North } \\
00\end{array}$ & $\begin{array}{c}\text { North } \\
01\end{array}$ & $\begin{array}{c}\text { North } \\
02\end{array}$ & $\begin{array}{c}\text { North } \\
04\end{array}$ & $\begin{array}{c}\text { East } \\
99\end{array}$ & $\begin{array}{c}\text { East } \\
00\end{array}$ & $\begin{array}{c}\text { East } \\
01\end{array}$ & $\begin{array}{c}\text { East } \\
02\end{array}$ & $\begin{array}{c}\text { East } \\
03\end{array}$ & $\begin{array}{c}\text { West } \\
99\end{array}$ & $\begin{array}{c}\text { West } \\
01\end{array}$ & $\begin{array}{c}\text { West } \\
02\end{array}$ & $\begin{array}{c}\text { South } \\
99\end{array}$ \\
\hline North 00 & 53.5 & & & & & & & & & & & & & \\
\hline North 01 & 58.1 & 65.8 & & & & & & & & & & & & \\
\hline North 02 & 54.7 & 64.3 & 76.4 & & & & & & & & & & & \\
\hline North 04 & 62.3 & 55.6 & 58.3 & 58.4 & & & & & & & & & & \\
\hline East 99 & 51.0 & 72.1 & 65.0 & 69.8 & 60.0 & & & & & & & & & \\
\hline East 00 & $\begin{array}{l}47.9 \\
\end{array}$ & 62.9 & 71.6 & 78.0 & 57.4 & 64.3 & & & & & & & & \\
\hline East 01 & 41.6 & 53.8 & 61.0 & 70.9 & 47.7 & 59.5 & 69.2 & & & & & & & \\
\hline East 02 & 48.5 & 54.8 & 63.2 & 74.6 & 52.2 & 60.8 & 65.6 & 65.6 & & & & & & \\
\hline East 03 & $\begin{array}{l}42.8 \\
4\end{array}$ & 47.3 & 48.0 & 51.0 & 36.0 & 41.1 & 47.4 & 55.4 & 49.5 & & & & & \\
\hline West 99 & 44.1 & 52.6 & $66 . \overline{3}$ & 60.0 & 50.1 & 49.5 & 61.6 & 53.2 & 49.0 & $40.2^{-}$ & & & & \\
\hline West 01 & 49.5 & 54.8 & 73.8 & 69.8 & 50.2 & 58.5 & 72.3 & 61.3 & 56.0 & 42.5 & 68.6 & & & \\
\hline West 02 & 55.7 & 52.8 & 65.3 & 61.9 & 49.3 & 54.3 & 58.1 & 61.9 & 57.0 & 58.1 & 56.3 & 62.4 & & \\
\hline South 99 & 5 & 58.1 & 68.2 & 59.3 & $\mathbf{5 6 . 1}$ & $\mathbf{5 8 . 2}$ & $\mathbf{5 8 . 4}$ & $\mathbf{5 0 . 4}$ & $\mathbf{5 1 . 3}$ & $\mathbf{3 4 . 4}$ & 72.8 & 60.9 & 52.6 & \\
\hline South 02 & 29.3 & 36.5 & 39.2 & 53.6 & 25.0 & 40.0 & 45.9 & 56.5 & 54.5 & 75.4 & 33.8 & 42.9 & 49.0 & 29.5 \\
\hline Summer & $\begin{array}{c}\text { North } \\
00\end{array}$ & $\begin{array}{c}\text { North } \\
01\end{array}$ & $\begin{array}{c}\text { North } \\
02\end{array}$ & $\begin{array}{c}\text { North } \\
03\end{array}$ & $\begin{array}{c}\text { South } \\
00\end{array}$ & $\begin{array}{c}\text { South } \\
01\end{array}$ & $\begin{array}{c}\text { South } \\
03\end{array}$ & & & & & & & \\
\hline North 01 & \begin{tabular}{|l|}
56.1 \\
\end{tabular} & & & & & & & & & & & & & \\
\hline North 02 & 65.2 & 59.5 & & & & & & & & & & & & \\
\hline North 03 & 59.9 & 71.5 & 74.9 & & & & & & & & & & & \\
\hline South 00 & 47.8 & 56.1 & 42.9 & 47.8 & & & & & & & & & & \\
\hline South 01 & 40.6 & 36.8 & 55.5 & 51.0 & 42.3 & & & & & & & & & \\
\hline South 03 & 53.1 & 64.2 & 57.2 & 67.0 & 61.9 & 56.5 & & & & & & & & \\
\hline West 02 & 42.9 & 42.1 & 47.1 & 43.4 & 55.4 & 50.1 & 46.8 & & & & & & & \\
\hline
\end{tabular}


(mean $S=47.5$ to $52.5 \%$; Table 5). Differences in diet were largely attributed to the dominance of pollock (22 to $24 \%$ of difference) and low proportion of salmon ( 7 to $10 \%$ of difference) in the south compared to the north, east, and west (Figs. $3 \& 4$ ).

Regional comparisons of summer diet were limited (Fig. 4). Diet composition averaged over 3 yr (2000, 2001, and 2003) differed significantly between north and south with a mid-range value of $\mathrm{R}$ of 0.44 (mean $S=51.6 \% ; \mathrm{p}=0.1$; Table 4 ). The most common summer prey in these 2 regions were arrowtooth flounder, salmon, smelts (including capelin), and sand lance (Fig. 4). Differences in diet composition between regions were mostly attributed to a high occurrence of salmon $(17 \%$ of difference) in the south and a relatively high occurrence of capelin and herring in the north (12 and $11 \%$ of the difference, respectively). Overlap in diet between north and west in summer 2002 was also low ( $S=47.1 \%$ ), and attributed to 4 prey species (salmon with 19\%, pollock with 15\%, sand lance with $14 \%$, and capelin with $12 \%$ of the difference).

\section{Seasonal variation in diet composition}

Seasonal variation in diet composition within regions was significant for collections in the north and west, but not in the east (Table 4). In the north, significant differences in diet occurred between summer and all other seasons (mean $S=41.8$ to $56.5 \%$; $\mathrm{R}=0.51$ to 1 , all $\mathrm{p}<0.05$ ), with 5 prey types contributing to $\geq 10 \%$ of observed differences in diet in at least 1 pair-wise seasonal comparison. Together, 23 to $27 \%$ of the difference in diets was attributed to the relatively high occurrence of capelin and salmon in summer. A relatively low occurrence of Pacific cod in summer attributed a further $11 \%$ to the difference between summer and spring, and a high occurrence of arrowtooth flounder in fall attributed $13 \%$. Sand lance was also more important in winter (10\% of difference) compared to in summer.

In the west, significant differences in diet composition were found between spring and both winter and fall (mean $S=59.3 \%$; R $=0.90$ and mean $S=54.2 \%$; $\mathrm{R}=0.94$, respectively; both pair-wise $\mathrm{p}=0.029$ ), and were largely (21 to $23 \%$ ) attributed to an over 2 -fold increase in the occurrence of herring in spring. A relatively low occurrence of sand lance in spring compared to fall and a high occurrence of pollock in winter compared to spring explained a further 10 to $12 \%$ of seasonal differences. In the east, no significant differences were found in diet composition between seasons, given the diet collections available (Table 4).

\section{Annual variation in diet composition}

Variation in diet composition between years was evident within all seasons and regions (Table 5). In general, interannual overlap in diet was lowest among spring and fall collections, whereas collections from the north and east generally displayed the greatest interannual variation in prey composition. Interannual differences in the diet in spring and fall were largely ( $\geq 10 \%$ of differences among years) attributed to variation in the relative occurrence of the most dominant prey: in spring, Pacific cod, arrowtooth flounder, and pollock and, in fall, arrowtooth flounder, salmon, pollock, and sand lance (Appendix 1).

The most marked interannual change in diet over the study period was the unusually high occurrence of pollock in fall 2003 in the east $(\mathrm{RO}=54 \%)$, which alone accounted for most (37 to $42 \%$ ) of the interannual differences in diet. In 2003, the occurrences of Pacific $\operatorname{cod}(\mathrm{RO}=6 \%)$ and sand lance $(\mathrm{RO}=2 \%)$ were also relatively low in fall compared to other years, and, together with pollock, explained 53 to $64 \%$ of the difference in diet among years in the east. Variation in the occurrence of these 3 species was also mirrored by changes in their relative abundance, suggesting their contribution to differences in diet composition in terms of biomass was significant. In contrast to the east, the occurrence of pollock in fall was unusually high in 2002 in the south $(\mathrm{RO}=53 \%)$ and west $(\mathrm{RO}=21 \%)$, whereas, in the north, it remained similar to previous years $(\mathrm{RO}=13 \%)$, but was unusually low in $2004(\mathrm{RO}=$ $2 \%$ ). Assessment of regional fluctuations in the occurrence of cod was limited due to the absence of data from fall 2003 in the north, south, and west.

Annual variation in the occurrence of lower ranked prey such as herring and capelin also contributed considerably to differences in diet among years. For example, during spring in the north, a large proportion (12 to $20 \%$ ) of annual diet variation was attributed to herring, the occurrence of which was relatively high in $2000(\mathrm{RO}=17 \%)$ and $2003(\mathrm{RO}=10 \%)$, but absent from scats in 2001 and low in $2002(\mathrm{RO}=2 \%$ ). A gradual decline in the occurrence of capelin in the north over the study period explained $\geq 10 \%$ of differences in diet among years in both spring and fall. In the east, an unusually high occurrence ( $\mathrm{RO}=21 \%)$ of Pacific sandfish in 2002 accounted for up to $23 \%$ of annual differences in diet.

\section{Diet diversity}

Diet diversity averaged over all collections was $2.50 \pm 0.31$ using the Shannon index $H^{\prime}($ ENS = 12) and $4.30 \pm 0.82$ using Merrick's DDI for 7 prey groups. 
Within each season, diet diversity was similar between regions (all pair-wise $U$-tests, p > 0.05), although spring diversity in the west $\left(H^{\prime}=2.34 \pm 0.23\right)$ was slightly lower and approached a significant difference compared to the diet in the north and east $(2.71 \pm 0.19$ and $2.68 \pm 0.05$, respectively; both pair-wise comparisons, $\mathrm{p}=0.08)$. Averaged across all regions, diet diversity differed significantly between summer and all other seasons (all pair-wise $U$-tests, p < 0.05), but was similar between winter, spring, and fall (all pair-wise $U$-tests, p > 0.1); diversity was lowest in summer $\left(H^{\prime}=\right.$ $2.22 \pm 0.25, \mathrm{ENS}=9)$ and highest in winter $(2.67 \pm 0.16$, ENS = 14), spring $(2.58 \pm 0.23$, ENS $=13)$, and fall $(2.45 \pm 0.38$, ENS $=12)$. Comparisons between annual collections in the non-breeding season indicated that diet diversity in $2001(2.78 \pm 0.10)$ was higher than in $2002(2.48 \pm 0.56 ; \quad U=15.500, \mathrm{p}=0.029)$ and 2003 $(2.38 \pm 0.42 ; U=4.000, \mathrm{p}=0.018)$, but not significantly different from $2000(2.68 \pm 0.19 ; U=21.500, \mathrm{p}=0.449)$. In contrast, diet diversity in summer (breeding season) was lowest in $2001(1.87 \pm 0.31)$, compared to 2000, 2002 , and $2003(2.38 \pm 0.03,2.33 \pm 0.07,2.28 \pm 0.04$, respectively). Analysis of DDIs identified similar patterns.

\section{DISCUSSION}

\section{Steller sea lion diet in Kodiak Archipelago}

In concordance with previous studies, the prey identified in the present study indicate that Steller sea lions Eumetopias jubatus are adept at foraging on a variety of prey including demersal, semi-demersal, and pelagic prey (Sinclair \& Zeppelin 2002, Brown et al. 2002, Waite \& Burkanov 2006, Trites et al. 2007b). The size range of prey consumed by sea lions was also wide, with prey up to $\sim 70 \mathrm{~cm}$ FL taken. Compared to previous studies in Alaska our study reports a far greater number of prey species, although the main prey identified were similar. Of the 76 prey types identified in the present study, 24 occurred with $\geq 10 \%$ FO in any 1 collection (Table 3). The 6 most dominant species across all collections, in order of overall occurrence, were sand lance, pollock, arrowtooth flounder, Pacific cod, salmon, and herring. However, there were significant differences in their proportional contribution among geographical regions, seasons, and years.

Over the study period (1999 to 2005) the diet averaged over all 4 seasons was dominated by herring, pollock, and sand lance in the west and arrowtooth flounder, sand lance, and salmon in the north. In the east, the non-summer diet (fall to spring) was dominated by pollock, Pacific cod, and sand lance, whereas the diet in the south was dominated by salmon, pollock, and arrowtooth flounder, over summer to fall. Within each season, diets were most similar between adjacent regions (Fig. 1); diets on the north and east side of Kodiak were relatively similar, whereas the diet on the western side of Kodiak differed markedly from all other regions. Seasonal collections in the south were too limited to establish the degree of diet overlap with the eastern region, but summer diets in the south differed from those in the north.

Regional and temporal differences in diet composition were largely attributed to variation in the relative occurrence of the main prey species. However, lower ranking prey such as capelin and Pacific sandfish increased in importance in some years. Within each region and season the ranking of the 3 to 4 dominant prey generally varied from year to year. The exceptions were winter collections in the north, which were consistently dominated by sand lance, and spring collections in the west, which were consistently dominated by herring. Even in summer, when diet diversity was low and largely dominated by a single species, the dominant prey species varied from year to year. In years when salmon dominated the summer diet in the north, arrowtooth flounder was dominant in the south and vice versa, except in 2000, when capelin dominated the diet in the north and arrowtooth flounder and sand lance occurred in similar proportions (26 and $22 \%$, respectively) in the south.

In general, seasonal patterns in occurrence of prey such as herring, salmon, and capelin reflected expected changes in availability of prey due to fish life-history stages. Herring and capelin typically increased in the diet in spring and summer, respectively, when spawning fish aggregate in bays in dense schools (Blackburn et al. 1981, Brown 2002). Similarly, the occurrence of salmon increased in summer and fall with the inshore migration of prespawning salmon (Groot \& Margolis 1991). The seasonal presence of arrowtooth flounder was variable among sites, but appeared to be lowest in winter and higher in summer. Pollock and sand lance were generally lowest over summer and highest in fall and winter, whereas cod was highest in winter and spring. However, without detailed information on the concurrent availability of prey, it is difficult to differentiate between changes that reflect seasonal availability of prey and changes that occur due to a decline in the availability of more preferred prey.

Spatial differences in the diet of sea lions most likely reflect the influence of local oceanographic and habitat features on the spatial distribution, composition, and abundance of fish communities (Robards et al. 1999a). Unfortunately there is limited information on the availability of most sea lion prey species. Most information 
currently available is based on commercial fisheries catch data and stock assessment surveys, which provide only a broad snapshot of prey availability during a limited time period and are not designed to target sea lion prey or areas in which they forage. Although a number of studies have attempted to determine the fine-scale availability of Steller sea lion prey in the vicinity of rookeries and haulouts (e.g. Mueter \& Norcross 2000b, Womble \& Sigler 2006), most data are limited in spatial scale or species sampled and confounded by the fact that little is still known of the foraging distribution of Steller sea lions.

The greatest difference between the diet of Steller sea lions in the different regions was the relatively high occurrence of herring in scats from the western side of Kodiak. Herring are found seasonally in all bays around Kodiak, but occur in substantially higher spawning biomass along the west coast of Kodiak and Afognak Islands (Gretsch 2004). Uganik Bay currently supports the largest and most consistent spring spawning stock of herring in the Kodiak area (Gretsch 2004) and is approximately $15 \mathrm{~km}$ north of Cape Ugat (Fig. 1), the haulout where west Kodiak scats were collected. The occurrence of herring in the diet of sea lions using Cape Ugat was highest during spring, corresponding to the dense aggregation of spawning fish in bays along the west coast. Herring abundance was also relatively high in winter and fall, reflecting the large aggregations of overwintering herring in the eastern Shelikof Strait and adjacent bays (Gretsch 2004). Aerial counts of sea lions conducted between 1999 and 2003 also indicated that Cape Ugat was used throughout the year by a large number of sea lions, with a marked increase in numbers over the herring prespawning and spawning period (March and April) (Wynne 2005). In contrast, sea lion numbers at Cape Ugat dropped over summer, most likely reflecting the movement of animals to breeding colonies on the east coast of Kodiak and possibly the movement of some animals to other areas of predictable or seasonally abundant prey. Low counts in summer at Cape Ugat have generally corresponded to seasonal peaks in sea lion numbers at Chief Cove, $\sim 20 \mathrm{~km}$ south of Cape Ugat, where sea lions have been observed to prey on salmon at setnet sites (Wynne 2005).

Given their extremely high energy content (Anthony et al. 2000) and local abundance, herring most likely provide an important seasonally predictable and energy-rich prey source in the nonbreeding season. Overwintering and spawning herring have also been noted as important prey for sea lions at a number of locations in southeast Alaska, where their distribution has been shown to influence the spatial distribution and abundance of Steller sea lions (Womble et al. 2005, Womble \& Sigler 2006). Fine-scale analysis of the spatial and temporal patterns in the diet of Steller sea lions in relation to trends in their use of terrestrial haulouts would greatly improve our understanding of the foraging behavior of this species and may assist in assessing what proportions of the population are utilizing particular prey resources.

Sand lance were a key prey item during all seasons for Steller sea lions throughout the Kodiak Archipelago and, like herring, are high in lipid content (Anthony et al. 2000). Sand lance are a small, semi-demersal, schooling species, commonly found in shallow nearshore habitats, where they burrow in fine gravel or sand substrates during darker periods, and forage diurnally in pelagic waters in densely aggregated schools close to their benthic refuge or further offshore (Robards et al. 1999b, Blackburn \& Anderson 1997). Sand lance are an important energy-rich forage fish for many piscivorous predators, and changes in their abundance can significantly affect the population dynamics of many species (see review by Wilson et al. 1999). Unlike herring, sand lance are thought to be less restricted by water temperatures and able to occupy a wider range of habitats (Abookire \& Piatt 2005), which may explain the relatively consistent contribution of sand lance to regional diets.

In the Kodiak area, pollock are broadly distributed over the outershelf and slope regions to shallower nearshore waters where it appears to be the most dominant demersal species (Mueter \& Norcross 2000a, Jackson 2006). However, the abundance and size of pollock in the nearshore waters of Kodiak vary spatially and seasonally, with marked interannual variations in abundance (Anderson \& Piatt 1999, Jackson 2006, Lowen 2007). Pollock biomass in nearshore waters typically declines in late winter with the migration of adults to offshore spawning areas in Shelikof Strait and gullies on the northeast side of Kodiak (Bailey et al. 1999, Wilson et al. 2005) and begins to increase again in late spring, with maximum biomass occurring in summer (Lowen 2007). In contrast, the occurrence of pollock in the diet of Steller sea lions at haulouts in the north and south was relatively low in summer compared to other seasons, suggesting a preference by sea lions for more energy-rich or accessible prey, such as salmon and capelin.

Interestingly, of the small forage fish captured in shrimp surveys in the Kodiak region in recent years, eulachon was the most abundant, over herring or capelin (Anderson \& Piatt 1999, Jackson 2006). However, eulachon were only recovered in $15 \%$ of all collections ( $\mathrm{n}=47$ ) between 1999 and 2005, and, when present, typically occurred at low frequencies ( $<9 \%$ FO). Eulachon have one of the highest energy densities of any forage fish in the North Pacific, second only to northern lampfish Thaleichhthys pacificus and 
markedly higher than herring and sand lance (Anthony et al. 2000). In some areas of southeast Alaska, prespawning aggregations of eulachon in spring are thought to be an important seasonal energy source for sea lions (Sigler et al. 2004, Womble et al. 2005). Eulachon spawning runs have been reported on the eastern side of Kodiak Island in the past (Blackburn et al. 1981), but are not known to concentrate in bays in the densities observed in southeast Alaska nor to attract large numbers of sea lions. When caught in survey trawls in bays around Kodiak, they generally occur in deeper water mixed with adult pollock (R. Foy unpubl. data). Therefore, although eulachon are far greater in energy content than herring or sand lance and, in some years, may occur in greater abundance, the energetic cost of foraging on a more dispersed prey at depths may outweigh the energetic benefit when alternative prey are available.

Detailed analysis of interannual trends in diet was limited due to variable sampling distributions among years and regions. However, there appeared to be an overall shift in the occurrence of some prey species over the study period, with an increase in pollock following 2002 and concurrent decline in sand lance and cod. These changes were more evident in the east than in other regions. An apparent decline in the catch per unit effort of Pacific cod from 2000 to 2005 was also noted in analysis of small-mesh shrimp surveys conducted in the Kodiak area (Litzow 2006). Interannual shifts in the contribution of capelin and sand lance to the diet of black-legged kittiwakes foraging on the east coast of Kodiak were also recorded, with a decline in sand lance and concurrent increase in capelin between 2001 and 2003 (Kildaw et al. 2005). At the time of analysis, results from concurrent Steller sea lion prey surveys on the northeast coast of Kodiak (R. Foy unpubl. data) were not available. However, future analysis of the fine-scale temporal and spatial availability of prey and oceanographic conditions over the study period will likely shed light on the factors influencing diet variability. To capture the range of variability in both sea lion diet and prey availability, it is important that future diet studies and assessment of prey availability or fisheries overlap are based on concurrent data collected over a number of years.

\section{Potential biases}

The data presented in our study provide the most comprehensive information available on diet composition of Steller sea lions in the Kodiak Archipelago and a measure of the spatial and temporal variation in prey consumed. Based on the prey accumulation curves, the samples retained in the analysis were considered suffi- cient to describe the general diet composition and to assess spatial and seasonal variation in the importance of major prey species (Table 1, Fig. 2). However, additional seasonal collections are required to determine the extent of variation in diet between the south and other regions of Kodiak.

As with other methods of diet analysis, such as stomach content analysis, prey DNA and stable isotope ratios, the use of hard remains in scats to reconstruct diet is not without biases. The limitations and biases associated with scat analysis have been discussed previously for Steller sea lions (Cottrell \& Trites 2002, Tollit et al. 2003, 2007, Joy et al. 2006) and other pinniped species (Dellinger \& Trillmich 1988) and primarily relate to differential rates of digestion and recovery of diagnostic structures between and within prey species. Steller sea lion scats contain few otoliths, and erosion from partial digestion is high. Identification of all diagnostic skeletal structures in addition to otoliths, as used in our study, increases the detection rate of many species (Olesiuk et al. 1990, Cottrell \& Trites 2002, Tollit et al. 2007). However, more robust bone structures from species such as pollock may have greater recovery rates compared to fragile structures of smaller species such as capelin and sand lance (Tollit et al. 2003, 2007). Therefore, the importance of small forage species may be underestimated in the present study. In addition, prey that leave no or few hard remains, or are preferentially regurgitated, such as cephalopods, will be underestimated (Tollit et al. 2007). In our study, only small cephalopod beaks and eye lenses were recovered from scats, but fragments of much larger beaks were sometimes found. The proportional contributions of other prey types, such as crustaceans, were also underrepresented because they left few identifiable remains and were difficult to enumerate. Prey recovered from scats are also thought to be biased towards prey consumed by seals just prior to hauling out and may not be representative of all prey consumed during a foraging trip. Crude passage rates for prey remains in captive Steller sea lions range from 2 to $3 \mathrm{~d}$, although some prey may be retained for longer and deposited over a greater period of time (Tollit et al. 1997, 2007). Thus, the consumption of some prey species may be quantified more accurately than that of others. However, assuming that the biases remain relatively constant across collections, conclusions about differences in diet are still valid.

The relative importance of prey in the present study was based largely on frequency of occurrence and did not take into account differences in the number and size of prey consumed. However, the rank of particular prey based on frequency of occurrence was similar to that based on relative abundance and the composite index incorporating occurrence and abundance (IIMP). 
Provided sample sizes are relatively large, FO indices can provide useful dietary information in the absence of biomass estimates (Olesiuk et al. 1990, Sinclair \& Zeppelin 2002, Tollit et al. 2007). However, the limitations and biases associated with scat analysis and the indices used should be taken into consideration when interpreting our results.

\section{Comparison with historical studies}

Our study identified a similar suite of prey as those noted in previous studies conducted in the Kodiak area (Merrick et al. 1997, Sinclair \& Zeppelin 2002). However, the dominance of the main prey differed markedly between studies. The most common prey identified in scats from the Kodiak region in the 1990s were pollock, arrowtooth flounder, salmon, and Pacific cod (Sinclair \& Zeppelin 2002). Pollock was the most dominant prey in summer and winter collections in the 1990s, whereas the average summer and winter diets from 2000 to 2004 were dominated by sand lance and arrowtooth flounder, respectively. Sand lance, which was important in most collections in the early 2000s, occurred infrequently in the 1990s, with an overall frequency of occurrence of 9.5 and $17.7 \%$ in summer and winter, respectively (Sinclair \& Zeppelin 2002). Small forage fish such as capelin and herring also appeared to be less important in the 1990s than in the present study.

Differences in the dominant prey in scat samples collected in the 1990s and early 2000s suggest that a temporal shift in diet composition may have occurred. Although some of the differences in proportional contribution of particular prey species are likely due to differences in sampling distributions between studies, the consistent dominance of pollock at individual sites sampled in the 1990s suggests an overall decline of the importance of pollock. Individual site collections in the 1990s were limited in sample size and pooled across variable years, which may introduce biases due to interannual variability in the consumption of pollock (present study) or strong recruitment years. However, the frequency of occurrence of pollock in the 1990s was consistently high among site samples, whereas sand lance was only ranked in the top 3 prey items at 1 site and occurred less frequently than pollock and Pacific cod (Sinclair \& Zeppelin 2002). The size of pollock recovered from sea lion scats from the Bering Sea and Gulf of Alaska between 1998 and 2000 (mean $\mathrm{FL}=39.3 \mathrm{~cm}$; SD = 14.3) (Zeppelin et al. 2004) was also larger than that from Kodiak between 1999 and 2005 (primarily 21 to $34 \mathrm{~cm}$ ). Although these size differences add weight to a temporal change in the contribution of pollock to the diet of sea lions, the degree of change remains unclear due to differences between studies, in sampling distributions, and in the use of digestive correction factors.

In exploring the possible relationship between diet and population decline in Steller sea lions, it has been suggested that diet diversity in the 1990s was lowest where the sharpest declines in Steller sea lion populations occurred (Merrick et al. 1997, Trites et al. 2007b). Furthermore, it was suggested that diet diversity may be a proxy for the overall energy content of diet, with low diet diversity equating to low energy content (Winship \& Trites 2003). In the Kodiak region in the early 2000s, diet diversity in summer (mean DDI $=3.9$ ) was higher than reported in the 1990s for the Gulf of Alaska (DDI = 2.8; Merrick et al. 1997), but lower than calculated for southeast Alaska (DDI $=4.8$; based on 7 prey categories, Trites et al. 2007b). Merrick et al. (1997) suggested that as diet diversity increased, the rate of population decline decreased; therefore, the higher diversity measured for Kodiak may reflect reduced rates of population decline between the 1990s and the period of this study (1999 to 2005). However, this trend was not demonstrated in diet studies conducted between 2000 and 2003 in Russian waters at the western extent of the population range, where some of the areas with the highest diversity also had the highest levels of population decline (Waite \& Burkanov 2006).

In interpreting relationships between diet diversity and population trends it must also be emphasized that diet diversity is based only on the number of prey groups consumed and by itself does not reflect the biomass or energy content of individual prey species. For example, diet diversity in spring on the west side of Kodiak was low (mean $H^{\prime}=2.3$ ) compared to in other regions, but was dominated by energy-rich herring. As highlighted by Waite \& Burkanov (2006), little can be inferred about the foraging success of populations from diet diversity measures without further information on prey availability and on the quality and quantity of prey consumed.

The diet composition and diversity derived from the analysis of scats collected from land may also be influenced by the age and sex structure of animals occupying the sites sampled. In our study, summer samples were collected mainly from haulouts with a mixed age and sex structure, whereas those analyzed by Sinclair \& Zeppelin (2002) and Trites et al. (2007b) were collected from rookeries dominated by adult females. Thus, differences in summer diet composition and diversity between studies may be, in part, due to age- and sex-specific differences in foraging behavior. At other times of the year scats have been collected from haulouts, which typically have a more diverse age and sex structure and are generally thought to be representative of the popu- 
lation as a whole. Future studies focused on age- and sex-specific diet may help in interpreting differences in regional and temporal diet composition, but, for many locations, segregated sites do not occur or are inaccessible. The use of DNA-based techniques for sex assignment of scats (e.g. Reed et al. 1997) may allow assessment of sources of variation in diet composition in future studies.

\section{CONCLUSIONS}

Our study presents the most comprehensive and recent description of the diet of Steller sea lions in the Kodiak Archipelago. The prey species identified in our study were relatively similar to the suite of prey consumed by sea lions in the 1990s, but differed markedly in their relative importance. Unlike diet studies in the 1990s, pollock was not the most dominant prey species. Although pollock was ranked second in importance overall based on frequency of occurrence, the contribution of pollock to the diet of Steller sea lions in the Kodiak Archipelago varied significantly among regions, seasons, and years. In contrast, sand lance was ranked the most dominant prey overall and was relatively consistent in importance across all regions, seasons, and years. In addition to sand lance, herring and capelin also appear to be important energy-rich prey for sea lions during part of the year. Unlike other dominant species that varied in their contribution from year to year, sand lance and herring were consistently dominant in the north in winter and in the west in spring, respectively. Thus, during the non-breeding season, sand lance and herring may provide a predictable and energy-rich prey resource for sea lions in the Kodiak Archipelago. The importance of these small forage species in the diet of sea lions may also be underestimated due to biases inherent in diet studies based on scat analysis.

As we predicted, the diet composition of Steller sea lions varied among geographical regions, most likely reflecting the influence of physical and oceanographic conditions on local prey availability. Pollock and Pacific cod were more important in the east compared to other regions, whereas arrowtooth flounder was more important in the north, herring in the west, and salmon in the south, at least over summer. Integration of concurrent fine-scale investigations into the local availability of prey will likely shed light on the diet variability and distribution of Steller sea lions. However, understanding how local- and broad-scale changes in prey availability and climatic conditions influence the population dynamics of sea lions will ultimately require a greater understanding of the spatial foraging behavior of Steller sea lions and how the temporal and spatial availability of prey affects diet choice of different age and sex groups.
Acknowledgements. We thank B. Witteveen, K. Hough, C. Foy, and numerous others who collected and processed scats. T. Walters of Maritime Helicopters provided safe and reliable pilotage. S. Crockford (Pacific Identifications) provided expert identification of prey remains. We thank 3 anonymous reviewers for their suggestions, which greatly improved this paper. This project was conducted as part of the Gulf Apex Predator-Prey (GAP) program and supported by the University of Alaska and a National Oceanic and Atmospheric Administration grant (NA16FX1270). Scat collections were carried out under National Marine Fisheries Service/National Marine Mammal Lab (NMML) Scientific Permit No. 782-1532, Alaska Maritime National Wildlife Refuge Permit No. 74500-00-030, and approved by the University of Alaska's Institutional Animal Care and Use Committee (Assurance No. 01-46, 05-21).

\section{LITERATURE CITED}

Abookire AA, Piatt JF (2005) Oceanographic conditions structure forage fishes into lipid-rich and lipid-poor communities in lower Cook Inlet, Alaska, USA. Mar Ecol Prog Ser 287:229-240

Anderson PJ, Piatt JF (1999) Community reorganization in the Gulf of Alaska following ocean climate regime shift. Mar Ecol Prog Ser 189:117-123

Anthony JA, Roby DD, Turco KR (2000) Lipid, content and energy density of forage fishes from the northern Gulf of Alaska. J Exp Mar Biol Ecol 248:53-78

Bailey KM, Quinn TJ II, Bentzen P, Grant WS (1999) Population structure and dynamics of walleye pollock, Theragra chalcogramma. Adv Mar Biol 37:179-255

Blackburn JE, Anderson PJ (1997) Pacific sand lance growth, seasonal availability, movements, catch variability, and food in the Kodiak-Cook Inlet area of Alaska. In: Forage fishes in marine ecosystems. Proceedings of the international symposium on the role of forage fishes in marine ecosystems. Alaska Sea Grant College Program Report No. 97-01, University of Alaska Fairbanks, AK, p 409-426

Blackburn JE, Jackson PB, Warner IM, Dick MH (1981) A survey for spawning forage fish on the east side of the Kodiak Archipelago by air and boat during spring and summer 1979. Final Report OCSEAP Research Unit No. 553, Alaska Department of Fish and Game, Kodiak, AK

Bray JR, Curtis JT (1957) An ordination of upland forest communities of southern Wisconsin. Ecol Monogr 27:325-349

> Brown ED (2002) Life history, distribution, and size structure of Pacific capelin in Prince William Sound and the northern Gulf of Alaska. ICES J Mar Sci 59:983-996

Brown RF, Riemer SD, Wright BE (2002) Population status and food habits of Steller sea lions in Oregon. Oregon State University contract (F0225A-01) report, Oregon Department of Fish and Wildlife, Corvallis, OR

Browne P, Laake JL, DeLong RL (2002) Improving pinniped diet analyses through identification of multiple skeletal structures in fecal samples. Fish Bull (Wash DC) 100: 423-433

Clarke KR, Warwick RM (2001) Change in marine communities: an approach to statistical analysis and interpretation, 2nd edn. Primer-e Ltd., Plymouth Marine Laboratory, Plymouth

Cottrell PE, Trites AW (2002) Classifying prey hard part structures recovered from fecal remains of captive Steller sea lions (Eumetopias jubatus). Mar Mamm Sci 18:525-539

Dellinger T, Trillmich F (1988) Estimating diet composition from scat analysis in otariid seals (Otariidae): Is it reliable? Can J Zool 66:1865-1870 
DeMaster D, Atkinson S (eds) (2002) Steller sea lion decline: Is it food? II. AK-SG-02-02, University of Alaska Sea Grant, Fairbanks, AK

DiCosimo J, Kimball N (2001) Groundfish of the Gulf of Alaska: species profile. North Pacific Fishery Management Council, Anchorage, AK

> Fiscus CH, Baines GA (1966) Food and feeding behavior of Steller and California sea lions. J Mammal 47:195-200

Fritz LW, Stinchcomb C (2005) Aerial, ship, and land-based surveys of Steller sea lion (Eumetopias jubatus) in the western stock in Alaska, June and July 2003 and 2004. NOAA Tech Memo NMFS-AFSC-153

García-Rodríguez FJ, Aurioles-Gamboa D (2004) Spatial and temporal variation in the diet of the California sea lion (Zalophus californianus) in the Gulf of California, Mexico. Fish Bull (Wash DC) 102:47-62

Gretsch D (2004) Kodiak management area herring fisheries annual management report, 2003. Alaskan Department of Fish and Game, Division of Commercial Fisheries, Regional Information Report No. 4K04-25, Kodiak, AK

Groot C, Margolis L (eds) (1991) Pacific salmon life histories. University of British Columbia Press, Vancouver, BC

> Guénette S, Heymans SJJ, Christensen V, Trites AW (2006) Ecosystem models show combined effects of fishing, predation, competition, and ocean productivity on Steller sea lions (Eumetopias jubatus) in Alaska. Can J Fish Aquat Sci 63:2495-2517

Hughes SE, Hirschhorn G (1979) The biology of walleye pollock, Theragra chalcogramma, in western Gulf of Alaska. Fish Bull (Wash DC) 77:263-274

Hyslop EJ (1980) Stomach contents analysis-a review of methods and their application. J Fish Biol 17:411-429

Imler RH, Sarber HR (1947) Harbor seals and sea lions in Alaska. United States Department of the Interior, Fish and Wildlife Service, Special Scientific Report No. 28, Washington, DC

Jackson DR (2006) Trawl survey of shrimp and forage fish in Alaska's Westward Region, 2005. Alaskan Department of Fish and Game, Fisheries Management Report No. 06-58, Anchorage, AK

Joy R, Tollit DJ, Laake JL, Trites AW (2006) Using simulations to evaluate reconstructions of sea lion diet from scats. In: Trites AW, Atkinson SK, DeMaster DP, Fritz LW, Gelatt TS, Rea LD, Wynne KM (eds) Sea lions of the world. Alaska Sea Grant College Program, University of Alaska Fairbanks, AK, p 205-221

Kildaw SD, Murra KM, Buck CL (2005) Black-legged kittiwakes as bio-indicators of marine conditions in the western Gulf of Alaska. In: Wynne KM, Foy R, Buck L (eds) Gulf Apex Predator-Prey study (GAP), final report (FY2001-2003), NOAA Grant NA16FX1270. University of Alaska Fairbanks, School of Fisheries and Ocean Sciences, Kodiak, AK, p 173-205

Litzow MA (2006) Climate regime shifts and community reorganization in the Gulf of Alaska: How do recent shifts compare with 1976/1977? ICES J Mar Sci 63:1386-1396

Loughlin TR (1997) Using the phylogeographic method to identify Steller sea lion stocks. In: Dizon AE, Chivers SJ, Perrin WF (eds) Molecular genetics of marine mammals. Spec. Publ. No. 3, Society for Marine Mammalogy, Orlando, FL, p 159-171

Loughlin TR, York AE (2000) An accounting of the sources of Steller sea lion mortality. Mar Fish Rev 62:40-45

Lowen ME (2007) Seasonal oceanographic influences on Pacific herring and walleye pollock distribution and abundance in nearshore embayments of Kodiak Island, Alaska. MS thesis, University of Alaska, Fairbanks, AK
Lowry LF, Frost KJ, Calkins DG, Swartzman GL, Hills S (1982) Feeding habits, food requirements, and status of Bering Sea marine mammals. Document 19:19A, North Pacific Fisheries Management Council, Anchorage, AK

MacArthur R (1965) Pattern of species diversity. Biol Rev Camb Philos Soc 40:510-533

Mathisen OA, Baade RT, Lopp RJ (1962) Breeding habits, growth and stomach contents of the Steller sea lion in Alaska. J Mammal 43:469-477

Mecklenburg CW, Mecklenburg TA, Thorsteinson LK (2002) Fishers of Alaska. American Fisheries Society, Bethesda, MD

Merrick R, Loughlin T (1997) Foraging behaviour of adult female and young-of-the-year Steller sea lions in Alaskan waters. Can J Zool 75:776-786

$>$ Merrick RL, Chumbley MK, Byrd GV (1997) Diet diversity of Steller sea lion (Eumetopias jubatus) and their populations decline in Alaska: a potential relationship. Can J Fish Aquat Sci 54:1342-1348

> Mueter FJ, Norcross BL (2000a) Changes in species composition of the demersal fish community in nearshore waters of Kodiak Island, Alaska. Can J Fish Aquat Sci 57:1169-1180

Mueter FJ, Norcross BL (2000b) Species composition and abundance of juvenile groundfishes around Steller sea lion Eumetopias jubatus rookeries in the Gulf of Alaska. Alsk Fish Res Bull 7:33-43

National Research Council (2003) Decline of the Steller sea lion in Alaskan waters: untangling food webs and fishing nets. The National Academic Press, Washington, DC

Olesiuk PF, Bigg MA, Ellis GM, Crockford SJ, Wigen RJ (1990) An assessment of the feeding habits of harbour seals (Phoca vitulina) in the Strait of Georgia British Columbia based on scat analysis. Can Tech Rep Fish Aquat Sci No. 1730

Pitcher KW (1981) Prey of the Steller sea lion, Eumetopias jubatus, in the Gulf of Alaska. Fish Bull (Wash DC) 79:467-472

Pitcher KW, Olesiuk PF, Brown RF, Lowry MS and others (2007) Abundance and distribution of the eastern North Pacific Steller sea lion (Eumetopias jubatus) population. Fish Bull (Wash DC) 107:102-115

Reed JZ, Tollit DJ, Thompson PM, Amos W (1997) Molecular scatology, the use of molecular genetic analysis to assign species, sex and individual identity to seal faeces. Mol Ecol 6:225-234

Robards MD, Piatt JF, Kettle AB, Abookire AA (1999a) Temporal and geographic variation in fish communities of lower Cook Inlet, Alaska. Fish Bull (Wash DC) 97:962-977

Robards MD, Piatt JF, Rose GA (1999b) Maturation, fecundity, and intertidal spawning of Pacific sand lance in the northern Gulf of Alaska. J Fish Biol 54:1050-1068

Schiffman S, Reynolds ML, Young FW (1981) Introduction to multidimensional scaling. Academic Press, New York

Sease JL, Taylor WP, Loughlin TR, Pitcher KW (2001) Aerial and land-based surveys of Steller sea lions (Eumetopias jubatus) from the western stock in Alaska, June and July 2001 and 2002. NOAA Tech Memo NMFS-AFSC-122

Sigler MF, Womble JN, Vollenweider JJ (2004) Availability to Steller sea lions Eumetopias jubatus of a seasonal prey source: a pre-spawning aggregation of eulachon Thaleichthys pacificus. Can J Fish Aquat Sci 61:1475?1484

Sinclair EH, Zeppelin TK (2002) Seasonal and spatial differences in diet in the western stock of Steller sea lion (Eumetopias jubatus). J Mammal 83:973-990

Thorsteinson FV, Lensink CJ (1962) Biological observations of Steller sea lions taken during an experimental harvest. J Wildl Manage 26:353-359 
Tollit DJ, Steward MJ, Thompson PM, Pierce GJ, Santos MB, Hughes S (1997) Species and size differences in the digestion of otoliths and beaks: implications of pinnipeds diet composition. Can J Fish Aquat Sci 54:105-119

Tollit DJ, Wong M, Winship AJ, Rosen DAS, Trites AW (2003) Quantifying errors associated with using prey skeletal structures from fecal samples to determine the diet of Steller sea lions (Eumetopias jubatus). Mar Mamm Sci 19:724-744

Tollit DJ, Heaslip SG, Zeppelin TK, Joy R, Call KA, Trites AW (2004) A method to improve size estimates of walleye pollock (Theragra chalcogramma) and Atka mackerel (Plurogrammus monopterygius) consumed by pinnipeds: digestive correction factors applied to bones and otoliths recovered in scats. Fish Bull (Wash DC) 102:498-508

Tollit DJ, Heaslip SG, Barrick RL, Trites AW (2007) Impact of diet-index selection and the digestion of prey hard remains on determining the diet of the Steller sea lion (Eumetopias jubatus). Can J Zool 85:1-15

Trites AW, Miller AJ, Maschner HDG, Alexander MA and others (2007a) Bottom-up forcing and the decline of Steller sea lions (Eumetopias jubatus) in Alaska: assessing the ocean climate hypothesis. Fish Oceanogr 16:46-67

Trites AW, Calkins DG, Winship AJ (2007b) Diet of Steller sea lions (Eumetopias jubatus) in Southeast Alaska, 1993-1999. Fish Bull (Wash DC) 105:234-248

Waite JN, Burkanov VN (2006) Steller sea lion feeding habits in Russian Far East, 2000-2003. In: Trites AW, Atkinson SK, DeMaster DP, Fritz LW, Gelatt TS, Rea LD, Wynne KM (eds) Sea lions of the world. Alaska Sea Grant College Program, University of Alaska Fairbanks, AK, p 223-234

Wilson MF, Armstrong RH, Robards MD, Piatt JF (1999) Sand lance as corner stone prey for predator populations. In:

Editorial responsibility: Otto Kinne,

Oldendorf/Luhe, Germany
Robards MD, Wilson MF, Armstrong, RH, Piatt JF (eds) Sand lance: a review of biology and predator relations and annotated bibliography. Research Paper PNW-RP-521, US Department of Agriculture, Forest Service, Pacific Northwest Research Station, Portland, OR, p 17-44

Wilson MT, Brown AL, Mier KL (2005) Geographic variation among age-0 walleye pollock (Theragra chalcogramma): Evidence of mesoscale variation in nursery quality? Fish Bull (Wash DC) 103:207-218

Winship AJ, Trites AW (2003) Prey consumption of Steller sea lions (Eumetopias jubatus) off Alaska: How much prey do they require? Fish Bull (Wash DC) 101:147-167

> Womble JN, Sigler MF (2006) Seasonal availability of abundant, energy-rich prey influences the abundance and diet of a marine predator, the Steller sea lion Eumetopias jubatus. Mar Ecol Prog Ser 325:281-293

Womble JN, Willson MF, Sigler MF, Kelly BP, VanBlaricom GR (2005) Distribution of Steller sea lions Eumetopias jubatus in relation to spring-spawning fish in SE Alaska. Mar Ecol Prog Ser 294:271-282

Wynne KM (2005) Aerial monitoring of terrestrial habitat use by Steller sea lions in the Kodiak Archipelago, 1999-2003. In: Wynne KM, Foy R, Buck L (eds) Gulf Apex Predator-Prey study (GAP) final report (FY2001-2003). NOAA Grant NA16FX1270, University of Alaska Fairbanks, School of Fisheries and Ocean Sciences Kodiak, AK, p 79-92

Zeppelin TK, Tollit DJ, Call KA, Orchard TJ, Gudmundson CJ (2004) Size of walleye pollock (Theragra chalcogramma) and Atka mackerel (Pleurogrammus monopterygius) consumed by the western stock of Steller sea lions (Eumetopias jubatus) in Alaska from 1998 to 2000. Fish Bull (Wash DC) 102:509-521

Submitted: July 31, 2007; Accepted: December 19, 2007 Proofs received from author(s): May 1, 2008 